\title{
Uncertainty-based decision-making in fire safety: analyzing the alternatives
}

Jaime E. Cadena ${ }^{a^{*}}$, Andres F. Osorio ${ }^{b}$, Jose L. Toreroc ${ }^{c}$, Genserik Reniers ${ }^{d}$, David Lange ${ }^{e}$

${ }^{a}$ The University of Queensland, Crn Staff House rd, St Lucia, QLD, Australia, je.cadena@uq.edu.au

'The University of Queensland, Crn Staff House rd, St Lucia, QLD, Australia, a.osorio@uq.edu.au

'University College London, Gower Street, London, UK, j.torero@ucl.ac.uk

dTU Delft, Jaffalaan 5, Delft, The Netherlands, g.I.I.m.e.reniers@tudelft.nl

'The University of Queensland, Crn Staff House rd, St Lucia, QLD, Australia, d.lange@uq.edu.au

*Corresponding author, je.cadena@uq.edu.au

Keywords: fire risk, fire safety engineering, risk assessment, uncertainties, uncertainty analysis

\section{Abstract}

Large accidents throughout the $20^{\text {th }}$ century marked the development of safety fields in engineering, devoted to better identify hazards, understand risks and properly manage them. While many such fields evolved rather quickly and moved from a compliance to a risk-based approach, Fire Safety Engineering (FSE) experienced a significant delay in this transition. While the current performance-based approach to FSE provides flexibility and capitalizes on learning from accidental events and other engineering disciplines, FSE is still in many respects decades behind other safety fields and a key issue for the future is how FSE can account for uncertainty in the decision making process. This work provides an overview of the main alternatives to account for uncertainty in safety studies within the context of FSE, including traditional probabilistic analyses and emerging approaches such as strength of knowledge. An example is used to illustrate the impact of the uncertainty analysis on the results of a simplified fire safety assessment. A structured evaluation is performed on each alternative to assess its ease of implementation and communication. The outcome is a compendium of advantages and disadvantages of the alternatives that constitute a toolbox for fire safety engineers to configure and use within their fire risk assessments. Process safety engineers are expected to gain an understanding of the similar and important challenges of FSE, it being directly relevant for process risk management and fire risk management in administrative buildings.

\section{Introduction}

\subsection{Aim of this paper}

Safety engineering covers a large range of specialized disciplines, including nuclear safety, chemical process safety and security, disaster and emergency management, reliability engineering and fire safety engineering (FSE).

The current approach to fire safety in the built environment places an undue focus on regulatory compliance, at the expense of demonstrating safety in the majority of cases [2]. Demonstration of safety requires a full consideration of the uncertainties inherent in a systems response as well as the response of the system to reasonable scenarios which may occur. Probabilistic risk assessments (PRA's) are a common means to assess complex systems which are intended to account for uncertainties and evaluate the response of a system to various reasonable scenarios. Various approaches to risk assessment in performance based design in Fire Safety Engineering are evidenced throughout the literature [3-6], however their outputs can yield potentially inaccurate results due to a lack of appreciation of the extent and nature of the uncertainties involved [7].

Process safety and FSE, which despite addressing hardly intersecting systems, share common challenges and potential solutions [1]. One of these challenges is how to account for and represent uncertainty in technical studies such as risk assessments. It is this challenge that is the focus of this work. Responding to a number of concerns identified in the literature, as well as concerns raised through discussions with experts in the fields of process safety and FSE this work presents a range of alternatives available for FSE practitioners to account for uncertainty. 
This introduction presents the challenges of accounting for uncertainty in current risk assessment practices, having a clear precedent in those faced by chemical process safety. Section 2 presents the main uncertainty analysis alternatives found in literature and describing them, section 3 implements them to a simple fire safety example. Section 4 evaluates the alternatives on a comparative basis and section 5 discusses the FSE challenges in light of the evaluation results, where we also describe interviews with expert practitioners which support the concerns in literature. Finally, section 6 presents the conclusions of this work and its role in addressing current FSE challenges. Despite being target towards the FSE community, this work is also relevant to the chemical process industry since administrative and storage buildings constitute key elements of a chemical processing business. Fire risks in these facilities must therefore also be adequately managed to ensure process safety and business continuity.

\subsection{Risk assessment supports decision making}

Fire events in Table 1 show that complex systems can fail and lead to major loss for all involved stakeholders. Similar events have led to the development of safety engineering fields such as nuclear safety and chemical process safety. Safety engineering within its purposes to support decision-making and properly manage risk. The formal process to do so is a risk assessment, made of hazards (and scenarios) identification, risk analysis and risk evaluation. The input of this process is information about the system such as physical characteristics and hazardous elements, while the outputs depend on the definition of risk and the analysis method. In general, the outputs of a risk assessment is the prioritization of risks, identifying those which are not acceptable in relation to a pre-defined acceptance criterion. Such output depends on the risk definition choice. Diverse definitions are available $[8,9]$ and the one by ISO 31000 [10] states that it is the effect of uncertainty on objectives. Aven et al. [11] have stated that definitions of risk impact the way it is understood and evaluated. Detailed analyses of the ontological origin of the risk concept and its evolution throughout time are provided by Beck [12] and Blokland and Reniers [13]. A popular definition for risk which enable many traditional risk assessment methodologies is that of consequences multiplied by likelihood, i.e. expected value.

Table 1. Examples of catastrophic events
\begin{tabular}{|l|l|l|l|l|l|}
\hline Event & Year & Location & Safety field & Human loss & Economic loss \\
\hline Collapse of World Trade Centre [14] & 2001 & $\begin{array}{l}\text { New York, } \\
\text { USA }\end{array}$ & Fire, security & $\begin{array}{l}2977 \\
\text { fatalities }\end{array}$ & US\$8B (buildings value) [15] \\
\hline Fire at Grenfell Tower [16] & 2017 & London, UK & Fire & 72 fatalities & $\begin{array}{l}\text { f50M (renovations and } \\
\text { enquiry) [17] }\end{array}$ \\
\hline $\begin{array}{l}\text { New Zealand International } \\
\text { Convention Centre fire [18] }\end{array}$ & 2019 & Auckland, NZ & Fire & - & $\begin{array}{l}\text { US\$26M (liquidated } \\
\text { damages over delays) }\end{array}$ \\
\hline Campbell chemical warehouse fire & 2019 & $\begin{array}{l}\text { Melbourne, } \\
\text { Australia }\end{array}$ & Fire, process & - & $\begin{array}{l}\text { Multi-million dollar clean up } \\
{[19]}\end{array}$ \\
\hline Chemical warehouses fires in Dhaka & 2019 & $\begin{array}{l}\text { Dhaka, } \\
\text { Bangladesh }\end{array}$ & Fire & $\begin{array}{l}81 \text { fatalities } \\
{[20]}\end{array}$ & Unknown \\
\hline
\end{tabular}

\subsection{Uncertainty in risk assessments}

A recognized issue of risk assessment is the presence of uncertainty sources, which can not only be numerous but correlated in complex ways. Before the scientific foundations of risk assessment were structured around 1945-1980 [21], many traditional engineering fields were already using its key features and managing the associated uncertainties. Structural engineering is an example relevant to FSE, where calculations needed to design a structure involve multiple complex variables and dependencies, which are modeled using well-known tools and parameters both of which involve considerable uncertainties, see Tallja et al. [22]. In this particular example uncertainties are identified and managed through 'experience from practical analysis' [22], i.e. expert judgment. As complexity grows, new approaches to account for uncertainties emerge, e.g. the comparison of the use of safety factors and reliability approach in structural design by Wang et al. [23]. Currently, risk assessment is recognized as a formal process and the core of the risk management process as defined by ISO 31000 [10] and Aven [24] presents a detailed analysis of its foundations, as well as of the way in which uncertainties are involved in the different steps. Using the example of 
the mature chemical process safety field, issues have been identified associated to the complacency of practitioners [25], the limits of prediction in risk assessments [26], the limits of the typically used probabilistic approach [27] and communicating uncertainties in the studies to the stakeholders [28]. In particular, Pasman and Rogers [29] conclude that risk analysts (engineers in charge of carrying out the risk assessment) are "haunted" by uncertainty while at the same time highlighting the vital role of risk assessments in supporting key decision making by stakeholders.

Safety science literature includes reviews on risk assessment methodologies, displaying approaches that adapt to different nature, complexity and magnitude of systems [30-32]. These reviews reflect not only the uniqueness and complexity of systems, but also the need to adapt the risk definition to better understand and manage uncertainty. Aven [27] clarifies that the purpose of risk assessment is not obtaining a risk index, e.g. Risk $=$ Likelihood $x$ Consequence, but obtaining 'an objective description of unknown quantities' or 'a scientific judgement about the unknown quantities' from the qualified safety engineers performing the risk assessment. A last and important consideration is that risk assessment foundations could lack coherence as they derive from reaction to catastrophic events and practical experience, rather than from a scientific approach [33]. This also poses a challenge to benchmark results and to unify guidelines. As highlighted by Aven and Kristensen [34] and the previously identified issues, it is a current priority of safety engineering fields to better understand uncertainty and its effect on risk assessments.

\subsection{Risk assessment issues in fire safety}

Most of the advancements of risk assessment have been undertaken in disciplines with a predominant performancebased approach, to which FSE has been transitioning since the appearance of the first performance-based construction codes, e.g. United States [35]. FSE has adapted risk assessment tools from other disciplines, however its framework does not provide the same basis for its structured and systematic implementation, as revealed by Hackitt [2], who in the aftermath of the Grenfell tower fire conducted an enquiry on the building safety provisions in the UK. An example is Approved Document A [36], which provides a wide range of accepted approaches to comply with the requirements of the building regulation, in particular those associated to the structural integrity of the building. Approved Document A requires an explicit and systematic risk assessment of buildings exceeding limits of area or number of stories. However, to implement such assessment there is limited guidance on the identification of fire scenarios for analyzing structural integrity [37]. The issues identified by Hackitt in the UK have also been identified in Australia [38] in the aftermath of less severe but equally concerning fires, such as the Lacrosse fire in Melbourne in 2014 [39].

The issues identified by the Shergold-Weir enquiry in Australia include lack of shared risk assessment practices, poor data collection and sharing, inadequate documentation (Recommendations 5, 8, 12, 14 [38]). The issues identified by the Hackitt enquiry in the UK include availability, completeness and updating of fire risk assessments, lack of a 'building safety manager', lack of a broad scope for risk assessments, management of changes and technical assumptions (Recommendations 3.2 - 3.4, 2.9, 9.3 [2]). These issues highlight a vast range of challenges, but are relevant here as many of them can be partially or largely tackled by implementing fire risk assessments where uncertainty is more clearly accounted for.

\subsection{Uncertainty sources in risk assessment}

The uncertainty sources in the context of performing a fire risk assessment are listed and described in Table 2 , minding that others sources exist and can be useful in the right context, including volitional uncertainty [40], dependence [41] and the taxonomy of deep uncertainty (ranging from known-knowns to unknown-unknowns) presented by Walker et al. [42]. Such structure is a product of the recompilation of the definitions provided by different sources and many of the works referenced in this study. First, Notariani and Parry [43] highlight the role of uncertainty in a typical fire risk assessment, from which the potential for switchover arises. Switchover is the change of performance evaluation criteria due to changes in the assumptions on which inputs and models are grounded. In simpler terms, when assumptions do not hold, the estimated performance might err in the unacceptable side and lead to design changes. This sets the main concern associated to poor uncertainty accounting in a fire risk assessment. Second, most PRAs are based on Kaplan's quantitative definition of uncertainty [44], therefore the 
uncertainty sources in Table 2 were formulated to be consistent with the three variables that compose it: scenarios, probabilities and their consequences. Finally, Aven's considerations of the different risk definitions make it clear that uncertainty accounting cannot be limited to a mathematical process and have to also incorporate ambiguity and vagueness, i.e. hard to quantify epistemic uncertainty sources [8].

It can be argued that uncertainty is only divided into epistemic and aleatoric and that linguistic elements are included in the former [45]; however, linguistic uncertainty as defined by Colyvan [46] is particularly relevant in the context of safety engineering fields. The use in FSE of risk acceptability criteria such as ALARP (as low as reasonably practicable) [5] and of performance-based requirements [47] which largely rely on linguistic elements, introduce this type of uncertainty which cannot be easily treated quantitatively. Johansen and Rausand [48] capture linguistic uncertainty within a broader category of ambiguity and provide a detailed accounting of how to identify and treat it within the process of a risk assessment.

Table 2. Uncertainty types in FSE

\begin{tabular}{|l|l|l|l|}
\hline Type of uncertainty & Epistemic & Aleatory & Ambiguity \\
\hline Description & Lack of or incomplete knowledge & Natural variability & $\begin{array}{l}\text { Vagueness, context dependency, } \\
\text { linguistic, under-specificity, } \\
\text { normative }\end{array}$ \\
\hline Context & $\begin{array}{l}\text { Complex systems and } \\
\text { phenomena }\end{array}$ & $\begin{array}{l}\text { Performance-based regulation, } \\
\text { criteria and guidelines }\end{array}$ \\
\hline Reduction methods & $\begin{array}{l}\text { New or improved theories based } \\
\text { on experimental observation }\end{array}$ & $\begin{array}{l}\text { Statistical studies to } \\
\text { characterize probability } \\
\text { distributions }\end{array}$ & $\begin{array}{l}\text { Consensus and alternative } \\
\text { interpretations }\end{array}$ \\
\hline $\begin{array}{l}\text { Residual } \\
\text { uncertainty after } \\
\text { reduction }\end{array}$ & $\begin{array}{l}\text { Deep uncertainty associated to } \\
\text { complex fire phenomena and } \\
\text { interactions }\end{array}$ & $\begin{array}{l}\text { Uncertainty associated to } \\
\text { extreme variations }\end{array}$ & Misinterpretation \\
\hline
\end{tabular}

A generic risk assessment process is shown in Figure 1, along with the typical uncertainty types fed to it. Propagating such uncertainties can be a procedural issue if all are deemed epistemic and expressed using classical or Bayesian probabilities; however, the process shows that different uncertainty types are mixed along the process, backing up Colyvan's [46] argument. Both Hackitt and Shergold-Weird enquiries [2,38] highlight the need of reducing vagueness and/or ambiguity from performance requirements used to evaluate a fire safety in a building. Such ambiguity and vagueness is not communicated and it is rather carried along the risk assessment process without explicit consideration. Notarianni [49] also notices this when discussing uncertainty sources in the FSE design process by stating that 'at present, performance criteria are not established or agreed on'. The relevance of this type of uncertainty in FSE is not clear as reflected by the uncertainty definition of the Society of Fire Protection Engineering (SFPE): 'amount by which an observed or calculated value might differ from the true value' [50]. This definition not only constitutes a narrow view of what risk and uncertainty are, but also greatly limits the capacity for practitioners to express uncertainty in studies where a probabilistic approach is not feasible or recommended.

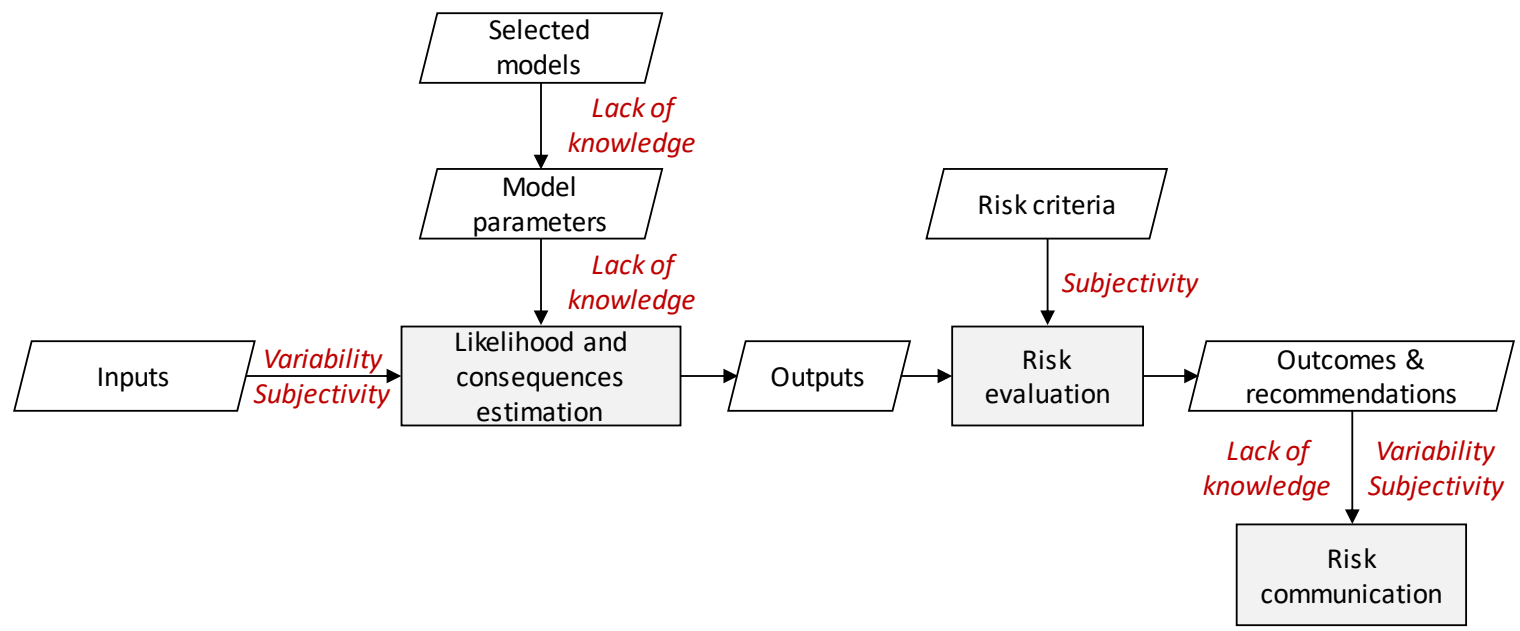


As presented in Table 2, epistemic uncertainty can be reduced through acquiring new information, i.e. evidence. With enough additional evidence, epistemic uncertainty can be reduced enough to make analysts comfortable with the outcomes of their risk assessments. Evidence can either update or improve prior knowledge on something already known, e.g. updating probabilities, or reveal new knowledge that did not exist, e.g. new failure modes. Failure modes or faulty assumptions are typically identified when catastrophic events occur. Such uncertainty is referred to as 'deep uncertainty' or the highest level of uncertainty according to Walker et al. [42] and cannot be treated in a probabilistic manner as Kaplan once proposed [51]. In a practical sense, probabilities can only be estimated for events (and the associated failure modes) that analysts can foresee. Unknown scenarios product of unrecognized failure modes or dependencies between existing ones, cannot be quantified and included in the risk description.

The variety of uncertainty sources and their type (including deep uncertainty) present a challenge for any risk assessment approach. Aven [52] provides a compilation of references in which risk assessments in general are deemed 'simplistic and unrealistic' and even misleading when the background knowledge of the analyst is poor. This draws relevance to this work and the identification of the different uncertainty analysis alternatives available for FSE practitioners.

\subsection{PRAs in FSE}

PRAs have their foundation in the Rasmussen study [53] and the theoretical basis provided by Kaplan [44]. Several references provide technical details of PRAs [54-57] and detailed examples include airports [58], liquid spill fires [59], natural events triggering technological events (NaTech; these are events where events such as floods interact with manmade systems to cause undesired events such as explosions) [60,61], hydrogen refueling stations [62], land-use planning [63], railway tunnels [64], urban road tunnels [65]. In short, in PRAs risk is defined as the triplet $\left\langle s_{i}, p_{i}, x_{i}\right\rangle$, where $i$ refers to an integer number representing a given scenario $(s), p$ refers to the probability of said scenario occurring and $x$ to its consequences. Both Amundrud [66] and Zio [67] highlight that PRAs are useful and their major advantage being scenario identification and risk sources comparison. Both of these elements are significant challenges in FSE, as the scenario identification is conditions to the complex relationship between the fire dynamics and the building response, which is often an output of the assessment rather than an input. Furthermore, comparing risk sources require underlying statistics than enable benchmarking the contribution different hazards or threats that can lead to an unwanted event. These statistics in FSE are not comparable to the level of detail and maturity than those in chemical process safety, notwithstanding these have their own limitations [68].

The previous entails that applying PRAs to account for uncertainty in FSE is not an ideal solution. PRAs are applied in FSE through the BS 7974 [69] and rely on statistical data of fire ignition and probabilities of failure for safety equipment such as sprinklers or mechanical extraction. Similar approaches in process safety have already been analyzed after decades of implementation, highlighting the potential for large uncertainty margins which are seldom reported $[70,71]$ and requiring new risk assessment perspectives [34, 72-78]. Such uncertainties threaten to render risk assessments useless in supporting decision-making and the new perspectives call for a need to understand them not as a mechanistic process, but as a complex evidence gathering exercise than effectively supports decisionmaking. FSE is not strange to this potential problems, as a probabilistic nature to fire risk is found in early fire safety engineering literature [79].

In the context of PRAs, Paté-Cornell [80] discusses how even a deterministic analysis can be useful in the right context. A deterministic analysis can provide insight on uncertainties given that it goes beyond a simple point-value result and includes variability in the form of error bars. Multiple deterministic models can provide a bound for the point-value estimate, and large random variability could call for fully probabilistic analyses. Regardless of the analysis approach, the need for uncertainty analysis is crucial and make necessary to know and weight the available alternatives to do so. These alternatives are introduced in the following section. 


\section{Uncertainty analysis options}

The approaches available for safety engineers to describe uncertainty go well beyond probability $[46,81]$ and this section identifies the main approaches through a bibliographical search, using Dubois's work [82] to guide the selection of search criteria (Table 3). The searches were conducted on Scopus ${ }^{\oplus}$ database which indexes key peerreviewed literature much related to the mentioned safety engineering fields. The data was retrieved on the $13^{\text {th }}$ of March of 2019 using a search timeframe between January 2000 and December 2018, limiting it only to journal articles. The table presents the search parameters, while Figure 2 presents the predominance of the probabilistic approach in journal papers production and the growing contribution of the other main alternatives.

Table 3. Searches and top results. *For the probabilistic, the results for 'non-probabilistic' were removed.

\begin{tabular}{|l|c|c|c|}
\hline \multicolumn{1}{|c|}{ Approach } & Number of articles (2000-2018) & Top subject area & Top author (No. publications) \\
\hline Probabilistic & $749^{*}$ & Engineering (28.4\%) & Aven, T. (11) \\
\hline Bayesian & 316 & Engineering (26.4\%) & Khan, F. (6) \\
\hline Fuzzy & 306 & Engineering (27.8\%) & Huang, G. H. (23) \\
\hline Possibility & 150 & Environmental (21.0\%) & Zio, E. (5) \\
\hline Belief & 82 & Engineering (11.6\%) & Tesfamariam, S. (4) \\
\hline
\end{tabular}

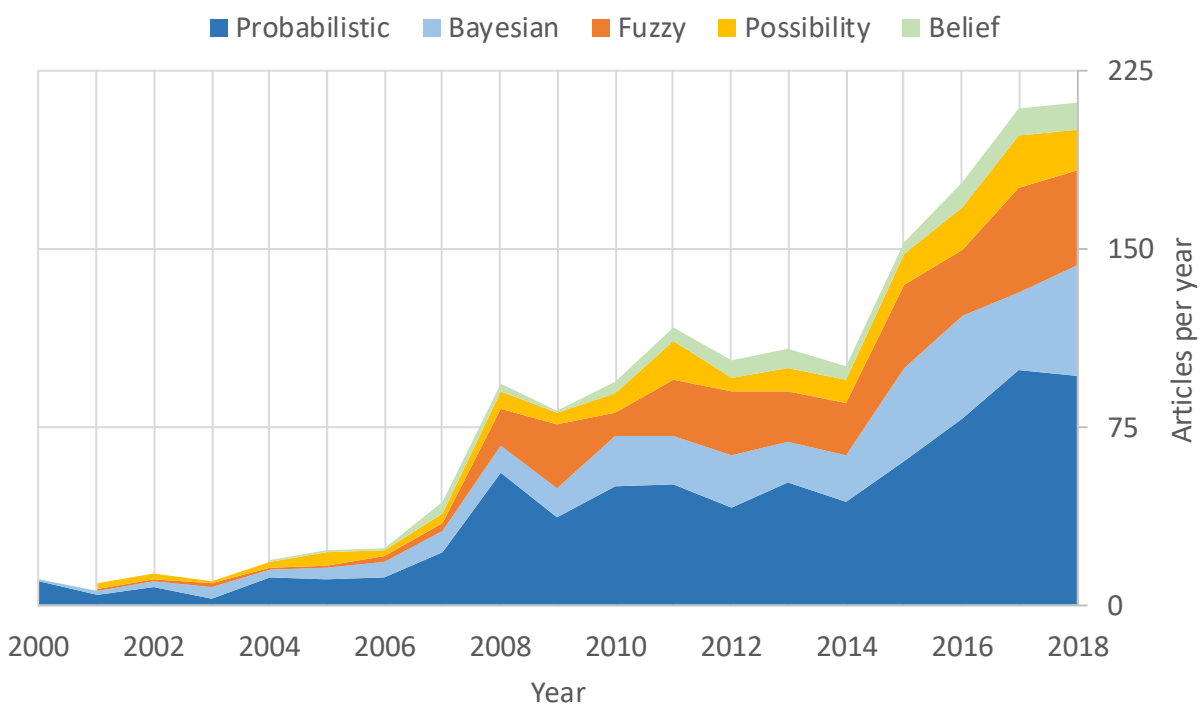

Figure 2. Results and annual growth for the main approaches to uncertainty analysis

This initial set of approaches to uncertainty analysis is further expanded by exploring selected papers. One of these papers is the detailed and well-structured description of the Generalized Information Theory (GIT) presented by Klir [83]. Another relevant work is the collation of imprecise-probability methods done by Beer [84], where the focus are problems where non-mutually exclusive sets are formulated $\left(1<\sum p_{i}\right.$, with $i$ being the set or possible outcome). Aven [85]provides a risk definition that accommodates these uncertainty analysis approaches beyond Kaplan's original quantitative definition [44]. In Aven's definition risk goes beyond scenarios (A) and their associated probabilities $(P)$ and consequences $(C)$, and replaces probability for an uncertainty descriptor $(Q)$. This definition also accounts for the supporting background knowledge of the analysts $(K)$, resulting in a definition of the form $R=f(A$, $\underline{C}, \mathrm{Q}, \mathrm{K}$ ), which easily accommodates both probabilistic and non-probabilistic approaches. Abdo et al. [86] apply a variety of the approaches reported by the previous references to an atmospheric dispersion of a toxic gas, obtaining a direct quantitative comparison based on the likelihood measure they provide.

GIT is a useful basis to begin the introduction to the existing alternatives, as it focuses on describing the degree of evidence existing to estimate the true value of a variable of interest $X$ within a specified set. A particular case of this is when the set is defined by the interval $[0,1]$. Klir calls these approaches uncertainty functions and include classical probability theory, possibility and evidence theory, and constitute the first approaches reviewed in this work, as presented in Table 4. 
Table 4. Uncertainty analysis alternatives within this work

\begin{tabular}{|c|l|l|l|}
\hline General approach & \multicolumn{1}{|c|}{ Specific approach } & Date & \multicolumn{1}{|c|}{ Main feature } \\
\hline \multirow{4}{*}{ Uncertainty functions } & Classical probability & 1977 & Additive, mapping onto [0,1] \\
\cline { 2 - 3 } & Possibility theory & 1978 & \multirow{3}{*}{ Non-additive, mapping onto [0,1] } \\
\cline { 2 - 3 } & Evidence theory & 1976 & \\
\cline { 2 - 3 } & P-boxes & 1987 & \\
\hline \multirow{3}{*}{ Robust Decision Making [87] } & Info-gap [88] & 2005 & Focus on robustness \\
\cline { 2 - 3 } & Strength of knowledge [34, 73, 76, 78] & 2017 & Assumption testing \\
\cline { 2 - 3 } & Exploratory Model Analysis [89] & 2003 & Scenario exploration \\
\hline
\end{tabular}

Uncertainty functions provide a numerical outcome of uncertainty contained in all the information available -or the lack of it- and this is not always possible to map onto the prescribed range. Klir recognizes alternative theories can fit within the GIT as long as they allow mapping uncertainty into the defined interval $[0,1]$ and highlights that the "choice of the uncertainty theory employed in dealing with each given problem should be determined by the nature of the problem itself" [83].

Beyond uncertainty functions, alternatives have arisen which focus on better supporting the decision-making despite the presence of considerable -unquantifiable- uncertainty both in the inputs used to define a scenario and in the assumptions used to model a system. Such alternatives are grouped under Robust decision making [87], which is defined is a framework designed to support decision-making under deep uncertainty. An example of these alternatives is the info-gap approach [88] in which the robustness is defined as an uncertainty horizon, i.e. a measure of how much uncertainty the system can resist. Such an approach helps engineers define satisfying performance requirements and allowing for variability in expected loads to the system.

The info-gap approach applied to structural problems with uncertain load variables [90] is in line with the performance assessment done by Cadena et al. [91] despite not specifying a robustness measure. In the latter, the assessment is accompanied by a judgment of its trustworthiness instead of a quantification of the robustness as in info-gap or of uncertainty as a probability. This trustworthiness judgment is done based on the approach formulated by Aven [34, 73, 76, 78] in which all quantities and associated assumptions within the model used are judged according to their strength of knowledge and output sensitivity. Exploratory Modelling Analysis (EMA) is another alternative that has been formulated under the Robust Decision Making framework. EMA makes use of computational power to run a large set of potential realities (scenarios) and then provide the information as a whole for stakeholder to support their decision.

\subsection{A note on inputs}

The nature of the input is key to any risk assessment, and also to uncertainty analysis. The approaches considered in this work do not specify a particular type of input. In general, inputs can be classified as quantitative or qualitative. The former can be used in risk assessments if qualitative criteria are used to define the variables of risk, e.g. probability and likelihood. Qualitative inputs can also be transformed into the latter using fuzzy numbers, which are variables with a specific formalized language.

Fuzzy numbers can be used as inputs for most of the approaches presented in this work and have the added value of expressing the membership function of a quantity of interest within a specified range. This allows engineers to describe their knowledge about the quantity as a function of degree of belief, rather than as a crisp function. A review of the use of fuzzy numbers in safety engineering is presented by Kabir and Papadopolous [92], while Shi [93] presents a building fire risk analysis using fuzzy numbers. Fuzzy numbers also reflect the need for engineers to use additional information rather than just a crisp value.

Numeral Unit Spread Assessment Pedigree (NUSAP) [94] constitute another type of input. NUSAP is a notational scheme that presents a numerical result along with information about the measurement and systematic error (Spread and Assessment, respectively) and the quality of what the number represents (Pedigree). NUSAP aims to provide decision makers with a more complete image of what a numerical result entails by taking into account its uncertainty as presented by Ellis et al. [95]. Given that pedigrees are subjectively defined categories, this constitutes 
an issue in propagating uncertainty and favor approaches such as fuzzy numbers or the recent alternative proposed by Zadeh [96], Z-numbers.

In this work, none of these notations are prioritized, as we acknowledge that the type of number used depends on the knowledge and confidence of the analyst in defining a variable. For the rest of this work, typical quantitative inputs will be considered, but the previous referenced work present applications of the uncertainty analysis approaches using different inputs.

\subsection{Probabilistic}

The idea of having a number that expresses how likely an event is to happen is very powerful and is in line with the intuitive meaning of likelihood [97]. The probabilistic alternative has as main characteristic that the possible values of the variable of interest $X$ are assumed independent and associated with random variation. By specifying the evidence theory framework, more precise estimates can be obtained, but less information is provided. In particular, the information associated to knowledge -and lack of it- is not explicitly presented in the estimates and a sense of completeness of knowledge is associated to the estimates; this is not always the case though. There are three distinct alternatives for a probability analysis: classical, frequentist and subjective. The former is analytical and evaluates the expected result against all possible results, e.g. rolling a dice, usually of little use in risk assessments. However, in fire risk assessments there are variables for which a uniform probability distribution is assumed, i.e. classical approach.

Frequentist alternative is suited to problems where a fully analytical approach is not possible, introducing random variables which can be probabilistically analyzed. This approach usually begins with recorded data that represents the behavior of the system to later analyze it and estimate future states of the system. This is done through logical constructions and random sampling. An example of the databases used in frequentist approaches is loss of containment databases such as [98] in which oil \& gas operators record and submit leaks and their main characteristics. Another relevant example of frequentist probabilistic analysis is the one carried out for the Cassini spaceship, where the aim was obtaining the probability of having a failure during the spacecraft's flight and then a reentry to Earth $[99,100]$. This is a case of interest given that the hazard related to the reentry to Earth was not the impact (with most materials melting in reentry) but the nuclear fuel. The report that describes the calculation [100] presents a detailed accounting of the diverse possibilities explored for a reentry to earth, which could only happen under very specific conditions which were deemed "highly unlikely". In the Cassini case the assumptions are clear and explicit, being supported by the engineers to show they are reliable. Almost two decades ago Apostolakis [101] presented the issue of focusing on obtaining estimates of the parameters that define a probability distribution which allows to gain insight to support a decision and claimed that such practice should be avoided. Not long ago Young [97] advocated for the same argument when analyzing research results that are the product of a large number of regressions. Apostolakis concluded that researchers should not only report preferred statistics and regression, but the whole body of models that they used. Evidently, all possible models cannot be considered and would not result useful either. Reporting on all models used could yield the technical analysis prohibitive from a time and economic resource point of view. In the context of risk assessment, the implications are similar when considering assumptions and associated uncertainty. The solution to this conundrum is a balance between detailed uncertainty description and professional competence to ensure the considerations of the study are adequate.

Subjective probabilities constitute a third approach, as mathematically structured by Savage [102] and also known as the Bayesian approach. This expresses the degree of belief towards a particular event from a set of states of the system, which can be 'updated' as new observations are obtained. Cooke [40] describes that this intuitive approach allows for 'rational decision' and the incorporation new evidence (e.g. additional relevant variables) from which knowledge increases and probability estimations are improved. In the context of fire risk assessments, the possibility of achieving such observations is not guaranteed.

Consider the design and construction of a mid-rise residential building which is intended for a life of no less than 40 years. Furthermore, consider that the architectural characteristics of this building do not match the boundaries of a prescriptive code and therefore a fire risk assessment must be done to explicitly demonstrate its safety level. Such assessment will depend on a large amount of variable from which information is limited and the best approach to account for them is the use of assumptions, as presented by Aven [34]. The updating of risk assessments (and 
validation of their assumptions) through the life-cycle of a system is addressed by Hackitt [2], who proposes a safety case approach for the approval process of high-risk buildings in the UK. In a chemical process plants requiring safety cases, dedicated stakeholders continuously work on the collection of new observations to optimize the operation and update the risk picture. This is not the case for most occupied buildings. An example is high-rise residential building where the building manager conducts administrative tasks to comply with code requirements, such as annual audits. However, there is not a figure that integrates, monitors and attend to all the components and systems that make up a fire safety strategy in a building. Throughout decades of research and unfortunate events, lessons have been learnt that improve this function, resulting in the identification and replacement of asbestos and the removal of fuel loads from critical locations such as fire doors. However, a fire risk assessment at the design stage is not typically updated later on unless significant changes occur. Even in this situation, there is not a framework that would call for the updating of the initial (a priori) probabilities embedded in a probabilistic fire risk assessment. The previous highlight that probabilistic -particularly Bayesian estimates- risk assessments in fire safety should not be the only option to express uncertainty, despite highly valuable if the monitoring of the system produced the required data to update the estimates of probabilities.

Bayesian networks (BN) allow decomposing complex dependencies between multiple variables, representing them graphically through nodes and links. BN are based in Bayes theorem, using known probabilities of basic elements to estimate the conditional probabilities of dependent elements. This is a powerful use of known probabilities to model unknown probabilities in complex systems such as estimating the dynamic operational risk assessment in a chemical process setting [103] or estimating the risk of human fatality in building fires [104]. As this method is based on conditional probability theory, its weaknesses are similar. Probability distributions for the random variables in the basic nodes are required, which can introduce engineers ' biases or assumptions that do not correspond to the system's reality; their effect can only be accounted for if they are made explicit.

\subsection{P-boxes}

This approach is the result of using probability theory and interval analysis [105] to produce probability boxes (Pboxes) which represent a class of distributions, instead of a single one. The class is a representation of the associated epistemic uncertainty and the variability (aleatory uncertainty). In typical probabilistic analysis, a variable of interest can be represented by a random variable with a given probability distribution function and its related statistics, but if this function is unknown, the interval approach can be applied to its distribution. By doing so the variable is circumscribed within upper and lower boundaries. Each boundary is also a probability distribution function and these can have a distinct shape, e.g. Exponential, or not, i.e. non-parametric. Whether the shape is well defined or not is a function of the available information to the engineers. This information is also the key of the simple but effective P-box approach, as well defined bounds for the variables of interest must be known in order to analytically obtain the upper and lower boundaries.

For a variable of interest $X$ with known minimum and maximum bounds, e.g. $[1,2]$, the non-parametric $p$-box would be the one in Figure $3 a$, while if information about $X$ allows assuming it distributes normally with bound on its mean and standard deviation, e.g. $\bar{X}=[1,1.75], \sigma=[0.1,0.3]$ the result is as in Figure $3 b$. This evidently provides the probabilistic approach with a higher flexibility, particularly when there is no confidence in point value estimates and the engineers prefer to express uncertainty as an interval. 


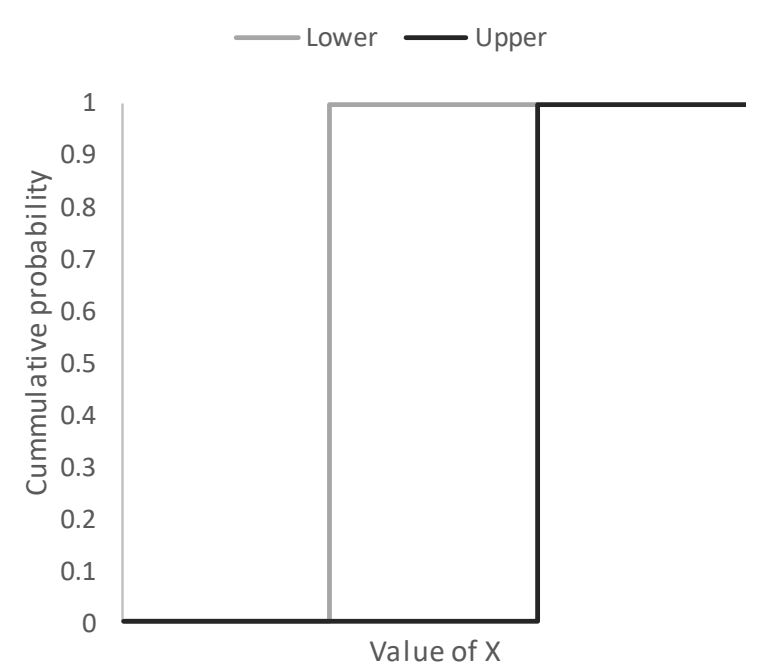

a)

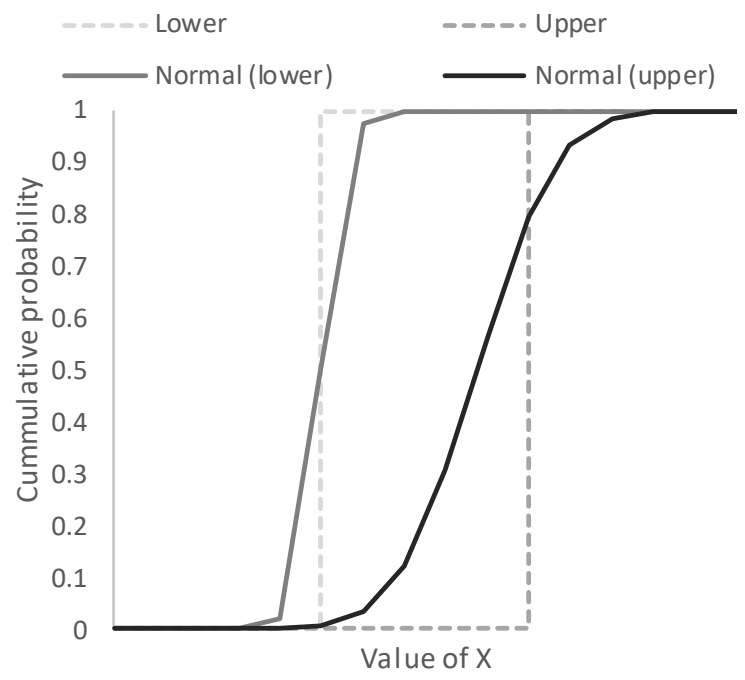

b)

Figure 3. a) P-box for known bounds of $X, b)$ P-box assuming a normally distributed $X$ with known bound on mean and standard deviation

\subsection{Evidence theory}

This first approach, based on the Dempster-Shafer theory, allows using different sources of evidence to support an estimate of the degree of belief. In the context of risk assessment this degree of belief is associated to the true value of a quantity of interest $(\mathrm{X})$. The uncertainty -or simply lack of knowledge- regarding the true value of this variable of interest is typically characterized in a probabilistic manner, as presented in section 2.2. In evidence theory the possible events -or values of the variable of interest- $\left(x_{1}, x_{2}, \ldots, x_{i}\right)$ are not constrained to single events, but to all possible subsets of events. Each of this possible events provide the analyst with a larger range of options to not only define a degree of belief of a single value, e.g. $x_{3}$, but to define the degree of uncertainty corresponding to combinations, e.g. $\left(\mathrm{x}_{1}, \mathrm{x}_{2}\right)$.

The previous is a generalization of probability theory, where the latter have a probability of zero, i.e. $P\left(X=x_{1}, x_{2}\right)=$ 0 . Evidence theory provides a platform to gauge the strength of evidence by defining a basic probability assessment or masses for each subset, e.g. $m\left(x_{1} \cup x_{2}\right)=0.1$. These masses are either obtained through expert elicitation or using the available data, allowing to define the belief and plausibility measures $(B e l(X), P I(X))$. These measures can be interpreted as upper and lower boundaries of the degree of belief, which supports making a prediction between to possible values $x_{1}, x_{2}$ given that $\operatorname{Bel}\left(x_{1}\right)$ is greater than the belief of all other possibilities.

Given the generalized form of this approach, it can be employed to process both probabilistic inputs and basic probability masses, as presented by Du [106] for the structural analysis of a machine. This provides an additional layer of information denoting lack of certainty regarding singleton values, which can be mapped into the same space in which probabilities are represented.

\subsection{Possibility theory}

Possibility theory is closely related to fuzzy variables, as these allow translating qualitative expert criteria into numbers. As described by Dell'Orco [107] and Darby [108], possibility theory with its necessity and possibility measures constitute the application of Dempster-Shafer theory to a problem in which the possible sets of the variables of interest are nested, and therefore non-conflicting. This means that any possibility for the variable, includes or is included in another subset.

This alternative provides engineers with an additional tool to express uncertainty in a case in which no conflicting evidence exist, but not enough evidence is available to have completely exclusive and independent sets. The latter is the special case of probability. This has been found to be the case for a large set of studies in the field of process safety, in which possibility theory is used to compute the risk assessment of different experts for a set of scenarios. 
Ouazari [109] presents the application to the Layers of Protection Analysis (LOPA), while Mandal [110] applies it to the Failure Modes and Effects Analysis (FMEA), both versatile and largely used process safety analyses. These examples show both the additional information conveyed by the results, in which risk is presented as a fuzzy number rather than a point-estimate (such a point-estimate can result from different de-fuzzification methods). In these examples the outcomes reflect the possibility and necessity measures, analogous to the previously presented belief and plausibility of belief theory.

\subsection{Info-gap}

The approaches presented up to now rely on the concept of likelihood, degree of belief or directly to the probability. In these, the uncertainty of the analyses is provided within the output as in the case of evidence measures. Info-gap is an alternative approach which was first proposed by Ben-Haim [88]. Info-gap's name points to the fact that there are information gaps within our models and therefore uncertainties that we need to manage, even in the extreme case in which the uncertainty level is so high that we cannot use one of the previously presented approaches.

Hayes [41] describes info-gap as one of the main approaches to deal with uncertainty and highlights its nonprobabilistic nature. This approach analyzes uncertainty from the perspective of how much uncertainty can the system handle, as a function of variations in the inputs and the parameters of the models used. This implies a considerable knowledge of the system and a model or set of models that allow obtaining an initial estimate, which in typical design approaches is used to obtain an optimized solution. Such solution is supported by a set of assumptions that in reality might not hold which if why info-gap provides a framework to test the resistance of the system to changes in them.

Ben-Haim [111] exemplifies info-gap as a framework to establish a safety factor on the results of the system. This non-probabilistic approach -despite its requirement for considerable high levels of knowledge- provides a different approach to uncertainty. Such an approach provides a solution that acknowledges the lack of knowledge and the impact this has on the system's response, instead of a frequency, probability or degree of belief.

\subsection{Strength of knowledge}

The idea of designing a system that involves uncertainty without addressing it as a probabilistic problem was presented with info-gap, but this is not the only approach. Strength of knowledge is another one of these approaches. It aims at identifying and managing assumptions and limitation used in an analysis and which could significantly affect its outcomes. Based on the studies published by its authors, Strength of Knowledge can be applied in different manners and it is flexible. In fact, it can be seen as a very general idea which is then tailored to suit the specific features of each problem, as presented in $[72,74,78,85,112]$.

In a typical risk assessment -either in chemical process or fire safety- assumptions usually are found everywhere, beginning with the information defining the system, then the construction of the scenarios, the models to estimate risk indices and to evaluate them. The general idea of Strength of Knowledge is to identify key assumptions made within a risk assessment and then judge whether they need to be addressed before communicating the results to the stakeholders. To judge the strength of knowledge a set of ordinal categories of qualitative or semi-quantitative nature are defined (e.g. low/medium/high) with their corresponding criteria, which are then used to judge each assumption.

The supporting knowledge for an assumption is not the only aspect that can impact the outcomes, as the sensitivity of these to a variation in the inputs or in the assumption is also key. This aspect is also judged for each assumption using another set of ordinal categories, which can be defined with purely quantitative criteria based on sensitivity ranges on the outputs. Qualitative criteria can also be used for assumptions that cannot be quantitatively assessed, requiring a competent expert formulating them and overseeing the judgment. The results can help identify a narrow range of potentially problematic assumptions requiring treatment. 
This treatment can be part of the risk assessment itself, such as further probabilistic analysis or the use of imprecise probabilities (e.g. evidence theory). If the resources are exhausted and at the end of the assessment there are still critical assumptions, these can be part of the decision making process and lead to establishing monitoring, control and mitigation measures that account for them not holding during the operation of the system.

\subsection{Exploratory Model Analysis}

Acknowledging the presence of deep uncertainties at different levels within and around a system, there is a need for uncertainty analysis alternatives that move further away from prediction and grow closer to the concept of robustness already introduced with the info-gap alternative. Exploratory Model Analysis presents a framework in which models are no longer used as the tool to find the exact answer or in the case of risk assessments, a failure prediction. Instead, models are recognized as the flawed constructions that they are and this is instead used to explore a wide range of plausible worlds, i.e. scenarios, and assess the response to particular decisions made by the stakeholders. In a risk assessment this means exploring how a large set of possible scenarios would react to different risk management strategies and decisions.

EMA can remove the mentioned burden on engineers and offer simpler approach to make the best out of the available models. Based on the work by Kwakkel [113], EMA can be described as in Figure 4 where the possible worlds are tested using different policies based on a model for the system. This constitutes a single computational experiment and each variation in the scenarios or the policy used generates different outcomes of interest. This differs from a typical engineering analysis in that all uncertainty sources are explicitly considered as part of the scenario, and allows analyzing the relation between these and the outcomes to identify those that produce higher sensitivity or breakpoints. Such process is the vulnerability analysis, which is complemented by the robustness evaluation of the outcomes that comes close to the robustness concept of the info-gap theory.

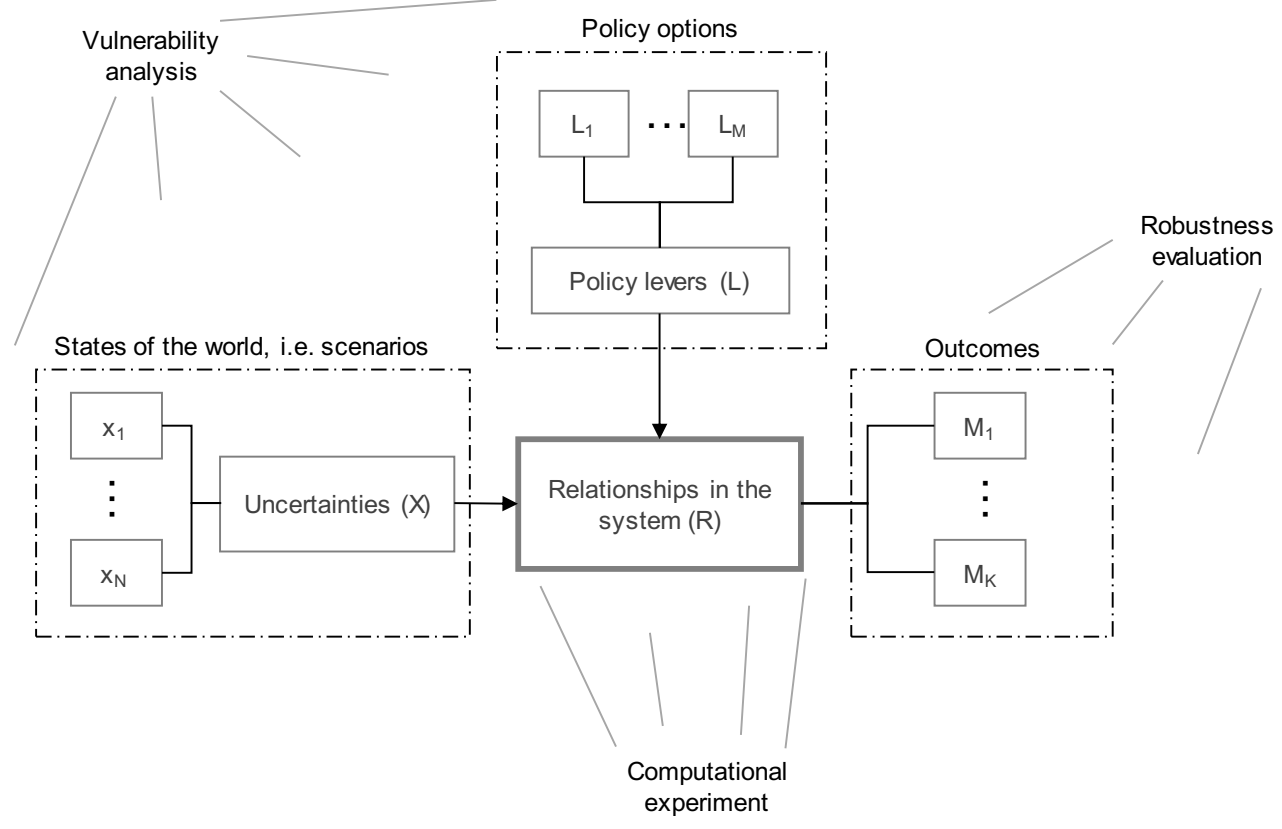

Figure 4. EMA process and main components based on [113]

EMA can be interpreted as an intelligent exploration of unknown realities using imperfect models, from which a prediction is impossible. The value of this approach is that it allows providing the key stakeholders with a comprehensive set of results that identify a policy that results in successful outcomes based on a given set of conditions within the scenarios. This is clearly and brilliantly exemplified by the implementation of EMA for the policy selection of water management of a river in the United States [114]. Given the simplicity of the compartment fire 
example EMA is not implemented as it would require increasing the complexity of the system to introduce the possibility of testing different risk management strategies.

\section{Case study: compartment fire}

To exemplify the differences between the presented alternatives a typical simple FSE example to illustrate them; both possibility theory and EMA are excluded. The former is excluded on the basis of its reliance on the additional fuzzy input from multiple practitioners, while the former is excluded as the simple nature of the example used does not support a wide range exploration as EMA intent.

The example used is the calculation of the descent of the smoke layer in a simple rectangular compartment of length $7 \mathrm{~m}$, width $5 \mathrm{~m}$ and height $3 \mathrm{~m}$ (total floor area $35 \mathrm{~m}^{2}$ ) with a door of width $1.5 \mathrm{~m}$ and height $2 \mathrm{~m}$. The compartment is of residential nature and expected to have a representative fuel load of polyurethane (PU) which is initially taken to have a distribution of $600 \mathrm{MJ} / \mathrm{m}^{2}$ [115]. Once ignited, the fuel is modelled with a heat release rate of $400 \mathrm{~kW} / \mathrm{m}^{2}$ and a medium rate of fire growth $\left(\alpha=0.0117 \mathrm{~kW} / \mathrm{s}^{2}\right)$. These two variables set the fire area and the growth of the fire, respectively. The fire is allowed to grow following a time-squared function until reaching the peak fire size.

Using the set of equations of Annex 1 based on energy and mass conservation, as well as some key experimental correlations, a suitable model is constructed to perform the calculation. The model is applicable for pre-flashover conditions and limits the peak fire size to $1 \mathrm{MW}$, which is one of the assumptions also registered in Annex 1 and discussed in the next sections. With a critical height established at 2 meters, the key output of the model is the time for the smoke layer to reach this level.

Assuming the previous input values without any uncertainty and applying them to the model, the result obtained is $58 \mathrm{~s}$. Such an output is key for available vs required egress time calculations in performance-based analysis and it is discussed related to the outcome provided by each approach and its advantages and disadvantages.

\subsection{Probabilistic}

To illustrate a simple application of the probabilistic approach, we use the compartment fire example. Not enough information exists to define the exact value of the fire growth rate, which can range from a slow growing fire $(\alpha=$ $\left.0.00293 \mathrm{~kW} / \mathrm{s}^{2}\right)$ to an ultra-fast one $\left(\alpha=0.1874 \mathrm{~kW} / \mathrm{s}^{2}\right)$ [116]. This leads to the engineers to formulate alpha as a continuous random variable, which according to Nilsson [117] distributes as a log-normal function with a mean of $0.01924 \mathrm{~kW} / \mathrm{s}^{2}$ and a specified $99.5^{\text {th }}$ percentile of $0.219 \mathrm{~kW} / \mathrm{s}^{2}$, which are the result of analyzing 2965 fires. By using a simple add-on to Microsoft Office Excel known as SIPmath [118], a Monte Carlo simulation is performed in order to sample the distribution as described by Figure 5 . After trialing different number of realizations, ten thousand was chosen as the first momentum of the distribution is stable at this point, noting that additional criteria can be used such as the second momentum.

The obtained samples are the input for the compartment fire model in which the time for the smoke layer reaching 2 meters can be calculated, yielding the results presented in Figure 6. The height of $2 \mathrm{~m}$ is chosen as it is above the average height at which occupants breath [119]. From this output it is possible to obtain the time for untenable conditions and therefore the available time for egress in the compartment, which for a $50^{\text {th }}$ percentile of 53 seconds and a $99^{\text {th }}$ percentile of 40 seconds. This indicates that there are fire scenarios in which extreme (but not impossible) scenarios can yield 18 seconds less than the previous output which did not account for uncertainty. Likewise, there are scenarios in which the time is as large as 89 seconds, which if taken into account could lead to underestimate the risk. These results do not account for particularly vulnerable occupants, such as those with movement impairment or simply those who are not awake and alert. This is part of scenario definition and becomes a limitation of the analysis, not always explicitly addressed. This is further discussed in the alternative presented in section 3.5. 


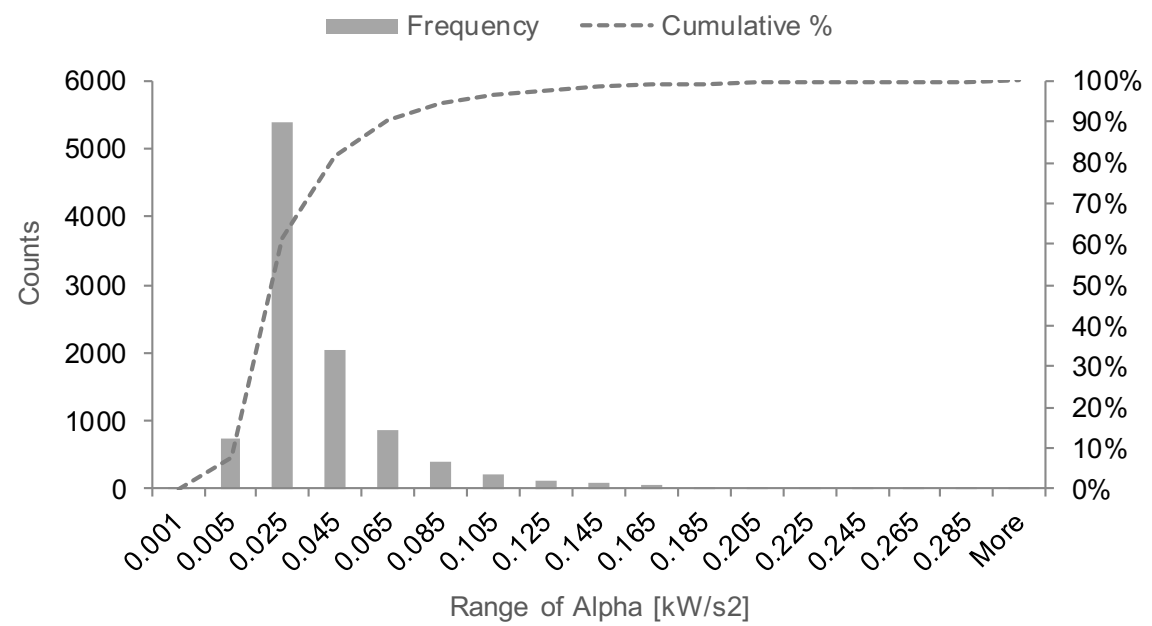

Figure 5. Fire growth alphas sampled for input of the probabilistic analysis

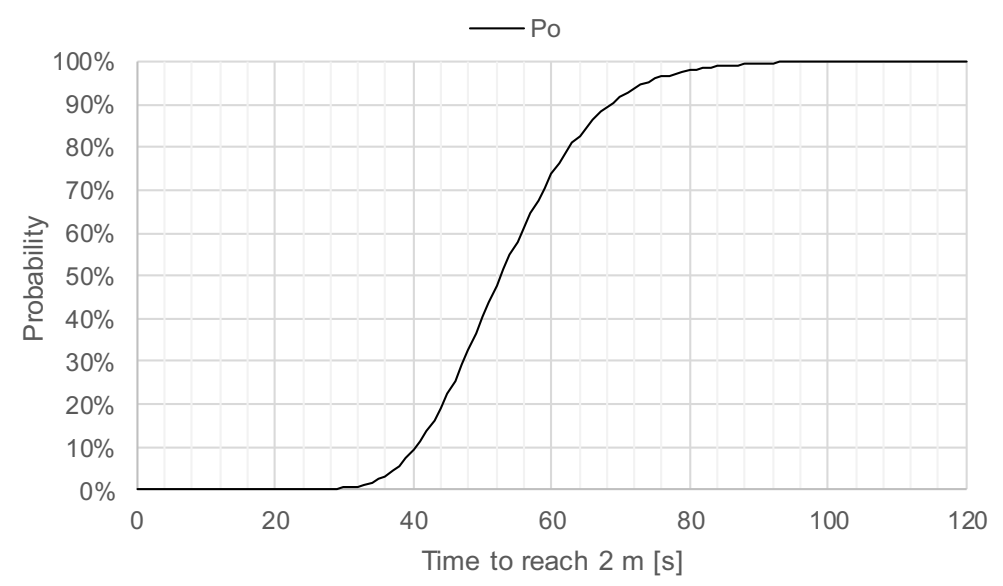

Figure 6. Resulting distribution for descent time

\subsection{P-boxes}

To construct the P-boxes for the compartment fire example, a range of distributions replaces a single probability distribution. This allows incorporating uncertainty on the distribution parameters, which for the case of the compartment fire and the time for the smoke layer to descend to 2 meters height are given by the 50th and 99.5 th percentiles of the lognormal distribution that described the fire growth coefficient, alpha.

Figure 7 presents the resulting $\mathrm{P}$-box having $\mathrm{P}_{\mathrm{o}}$, the previous single distribution, $\mathrm{P}_{1}$ a and $\mathrm{P}_{2}$. The new distributions respond to the analyst considering different conditions than the ones initially introduced in the previous section. $\mathrm{P}_{1}$ rules out possible arson in the compartment, which leads to a lognormal distribution with $50^{\text {th }}$ and $99.5^{\text {th }}$ percentiles of $0.011 \mathrm{~kW} / \mathrm{s}^{2}$ and $0.105 \mathrm{~kW} / \mathrm{s}^{2} . \mathrm{P}_{2}$ is a pessimist view of the analyst, based on the fact that the data used for the previous distributions do not match exactly the nature of the compartment. 


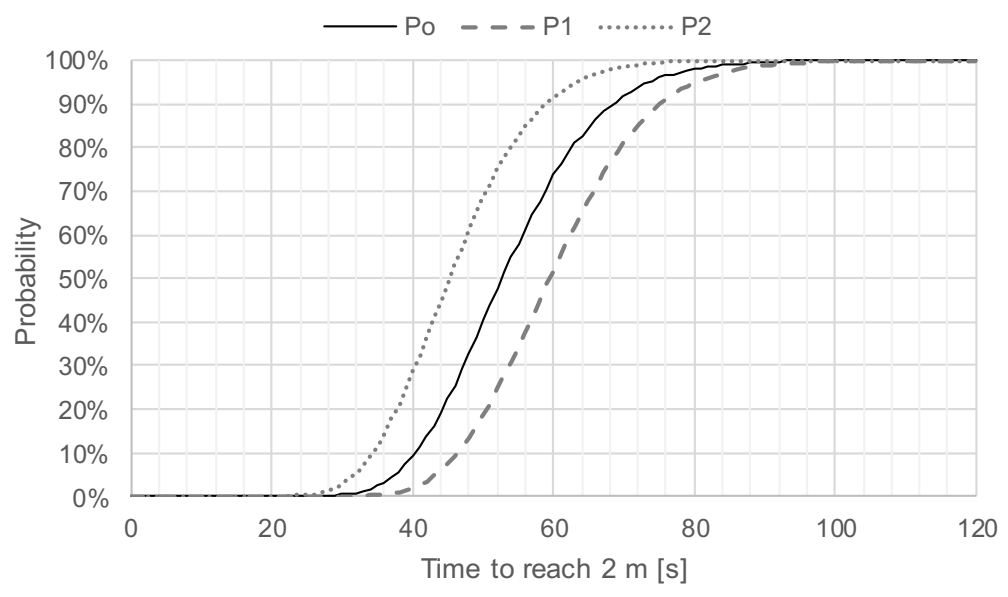

Figure 7. P-box for the descend of the smoke layer height

In order to present a more onerous scenario, the parameters of $\mathrm{P}_{\mathrm{o}}$ are doubled, resulting in a lognormal distribution with $50^{\text {th }}$ and $99.5^{\text {th }}$ percentiles of $0.0385 \mathrm{~kW} / \mathrm{s}^{2}$ and $0.438 \mathrm{~kW} / \mathrm{s}^{2}$. Here, specifying a range becomes harder, as now there are three distributions for which the results could be reported. Using the results of Figure 7 , the original result of $58 \mathrm{~s}$ has a $45 \%$ probability in the pessimistic $\mathrm{P}_{2}$ distribution, which could lead analyst to further hesitate in using such result. This of course translates into confidence boundaries and is an ideal tool to better understand the uncertainty of the calculation. With occupants' walking speed potentially under $1 \mathrm{~m} / \mathrm{s}$ given they are sleeping or have a disability, the result of the P-box could help identify potential improvements to reduce egress path length.

The disadvantage for the use of such results is that their communication can mislead stakeholders in believing that the worst possible conditions are covered, which might not be the case depending on the engineers' trustworthiness on their assumptions such as the pessimistic parameters of $\mathrm{P}_{2}$. As additional data becomes available such as that presented by Hopkin et al. [120], the possibilities for incorporating different conditions further enable the use of $\mathrm{P}$ boxes.

\subsection{Evidence theory}

Back to the compartment fire example, the evidence theory is applied to conflicting information regarding the fire growth rate. The fire engineers are unsure of the correct rate to use in the calculation as the compartment's lining materials are not specified and can contribute to different fire growth rates. This provides a considerable large range of possible fire growth rates, leading to the use of probability masses for the slow (S), medium ( $m$ ) and fast (F) rates. The frame of discernment is therefore $\theta=\{S, M, F\}$ and a power set: $2^{\theta}=$ $\{\varnothing, S, M, F,(S, M),(S, F),(M, F),(S, M, F)\}$. For these eight focal elements, the two experts are asked to provide the basic probability assignments with $m(\varnothing)=0$, which is presented in Figure 8 . 

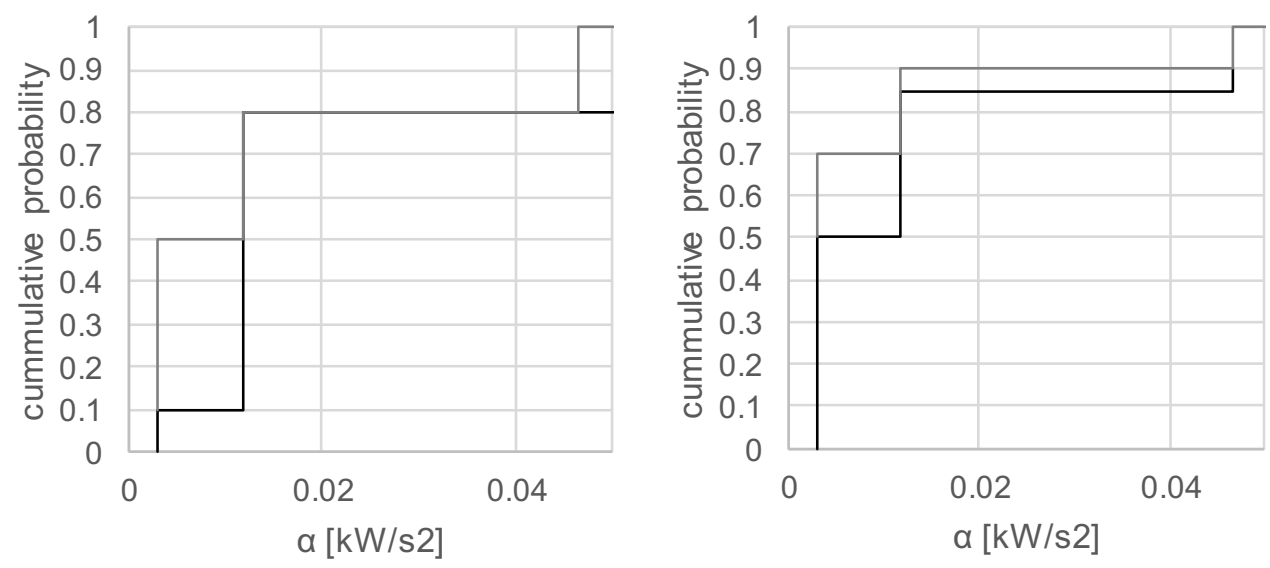

Figure 8. Dempster-Shafer structures for fire growth rate based on two experts' opinion

Disparity between the experts in their opinion is evident, which is common in the context of risk assessments [121] and could result in enhancement of the results [122]. Particularly, discrepancies might be found between third party reviewers and the opinion of the fire services, which might want the consideration of more onerous fire scenarios. By applying Dempster's rule of combination, these two independent structures can be combined and the resulting structure used to estimate the quantity of interest, i.e. time for the smoke layer to descend to $2 \mathrm{~m}$ height.

The results for the resulting structure for the quantity of interest are presented in Figure 9 . The results indicate that this time could be in the range between 41 and 17 seconds, with the former having a $40 \%$ likelihood and the range between 23 and 17 seconds one of $24 \%$. Although this information -as with P-box analysis- does not provide a pointvalue answer, it enables combining evidence provided by multiple experts and obtaining a simple but clear result which could support the need to explore further design fires.

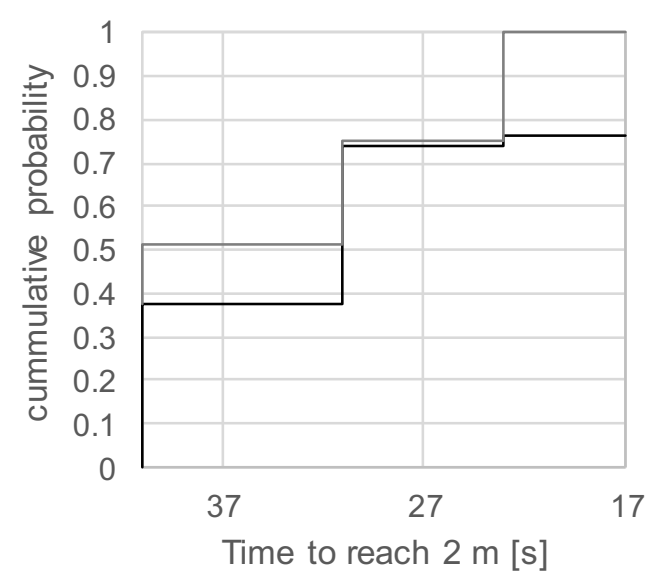

Figure 9. Dempster-Shafer structure resulting for the time to reach $2 \mathrm{~m}$ based on two experts input

One possible application of the Dempster-Shafer theory is using structures such as those in Figure 8 to construct probabilistic distributions and then assessing the belief and plausibility of a whole family of these. Such application can again be applied to our example, this time moving away from different engineers providing evidence, to a single one which provides a belief structure for the parameters of the lognormal probabilistic distribution considered in sections 2.2 and 2.3. The analyst defines the ranges for the parameters of the distribution as presented in Table 5, which are computed using the IP Toolbox add on for Matlab and yields the results of Figure 10. This graph provides the result for the belief and plausibility measures for the evidence provided and it is compared to the possible P-box resulting from using the extreme values of the ranges of Table 5.

Table 5. Evidence for constructing the distribution of the fire growth rate 


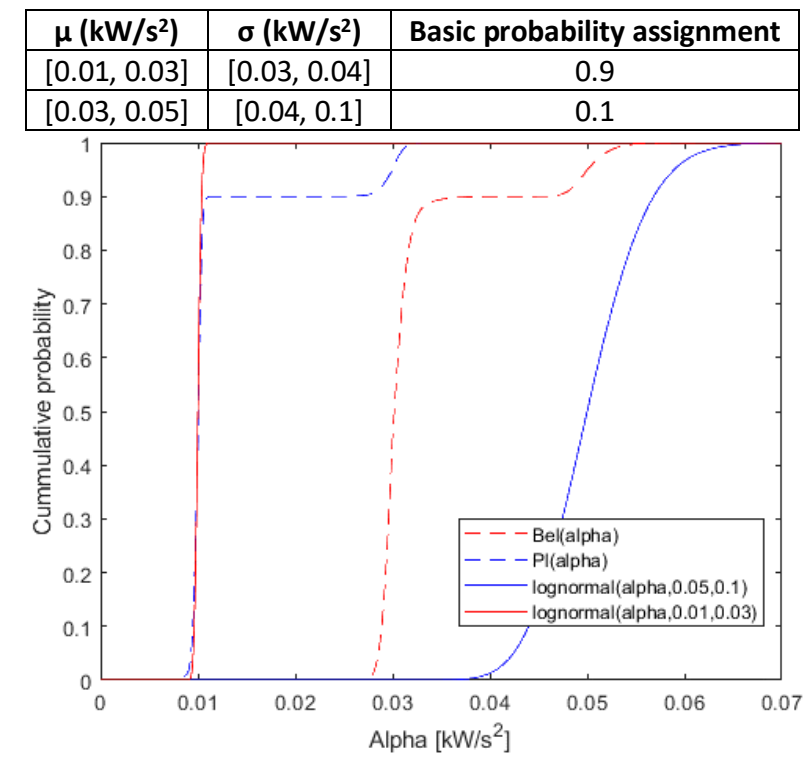

Figure 10.Belief and plausibility measures for the lognormal distribution with uncertain parameters

The comparison shows that indeed the evidence measurements provide additional insight to the possible ranges in which the 'real' distribution might be found, which are much narrower than those provided by the P-boxes. Using these results, the time for the smoke layer to reach 2 meters height can be estimated for the $50^{\text {th }}$ and $95^{\text {th }}$ percentiles, yielding the ranges $[25 \mathrm{~s}, 32 \mathrm{~s}]$ and $[22 \mathrm{~s}, 25 \mathrm{~s}]$, respectively.

Although the example presented does not include significant conflicting information, the Dempster-Shafer theory does allow for the inclusion of this type of conflicting evidence [107]. The main takeaway from this example is the possibility of narrowing down on specific scenario sets using subjective inputs and the providing a quantitative description of the likelihood, including an upper (Plausibility) and a lower bound (Belief).

\subsection{Info-gap}

Ferson and Tucker [123] provide an understanding on how to implement the info-gap approach using probability bounds, i.e. P-boxes. Info-gap is implemented following the safety factor concept. Specifically, four alternatives are presented and info-gap theory does not prescribe any particular one, as the analyst must decide which approach better fits each system. The approaches presented by Ferson and Tucker are practical and require a robustness measure (named alpha, for clarity referred here as $\alpha_{R}$ ) which is applied for the inputs of the system and allow identifying the level at which the system's response is no longer acceptable. This measure is applied to confidence bounds, e.g. Kolmogorov-Smirnov for empirical distributions, proportional bounds, distribution shift and a validation metric.

The previous ideas are in line with that of Cadena [91] when assessing fire risk through the concept of maximum allowable damage in a building for life safety, as an alternative to typical probabilistic approaches. These approaches are applied to the fire growth rate distribution presented in section 2.2 from the compartment fire example. First, an exponential function is defined which increases the P-boxes proportionally to the value of the fire growth rate (Figure 11), followed by multiplying $\alpha_{R}$ and the critical value of the Kolmogorov-Smirnov test to the nominal distribution, both for a confidence of $1 \%$ and $20 \%$ (Figure 12); the latter provides a wider P-box. 


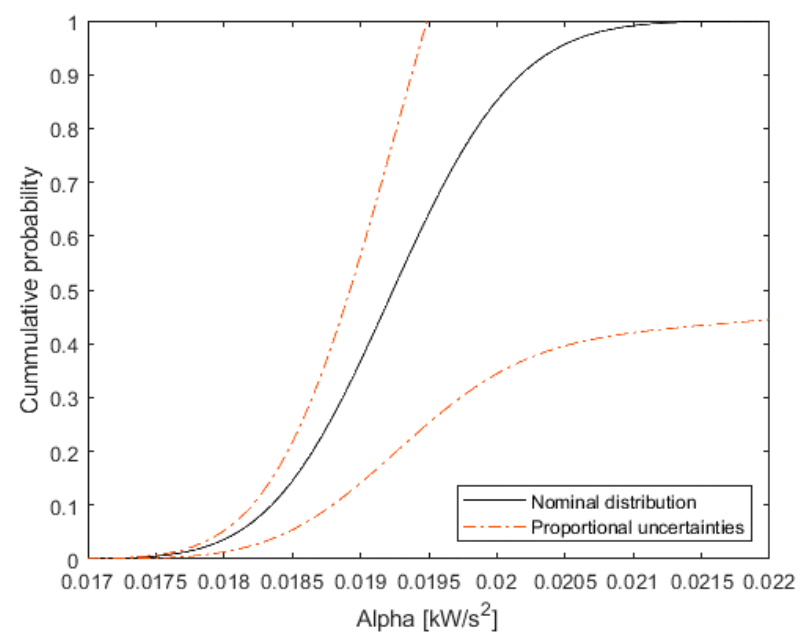

Figure 11. (Left) Info-gap concept applied to P-boxes through proportional uncertainty
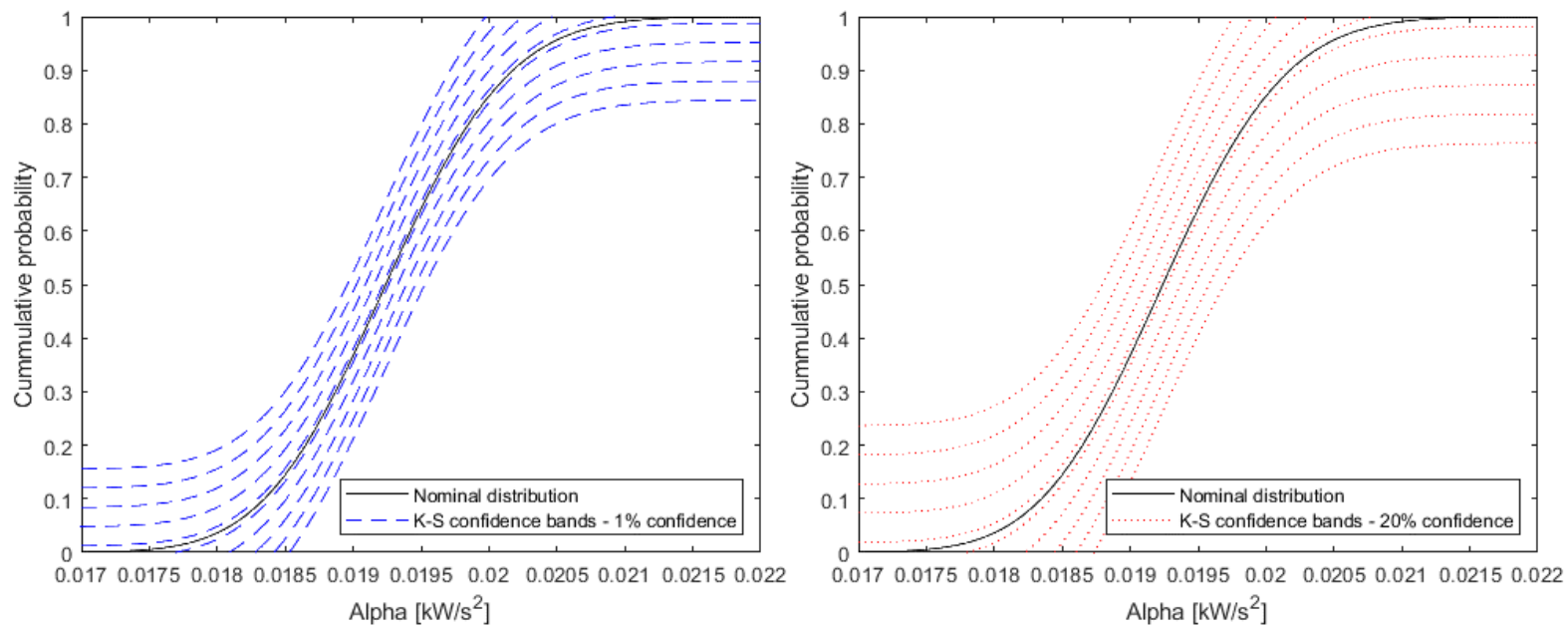

Figure 12. Application of info-gap with Kolmogorov-Smirnov confidence bounds and $\alpha_{R}$ between 1 and 20

Applying the $\alpha_{R}$ to the nominal distribution original range and generates a simple but effective set of inputs, given that a fire growth step is established (a value of $0.01 \mathrm{~kW} / \mathrm{s}^{2}$ is selected). With this simple application of the robustness measure, the time for the smoke layer to reach $2 \mathrm{~m}$ can be tested until it reaches a critical value, defined as the time it takes for an occupant to egress from the room. Based on the maximum path distance of $12 \mathrm{~m}$ within the room and a walking speed of $0.7 \mathrm{~m} / \mathrm{s}$, this critical time is $16 \mathrm{~s}$. A value of $\alpha_{R}>17$ is required for the fire growth rate to reach ultra-fast $\left(\sim 0.19 \mathrm{~kW} / \mathrm{s}^{2}\right)$ and yield a time of 16 seconds for the smoke layer to descend to $2 \mathrm{~m}$ height. As the value of $\alpha_{R}$ increases, so does the confidence on the result, which goes from $5 \%$ for $\alpha_{R}=16.95$ to $90 \%$ for $\alpha_{R}=17.17$ (Figure 14). 


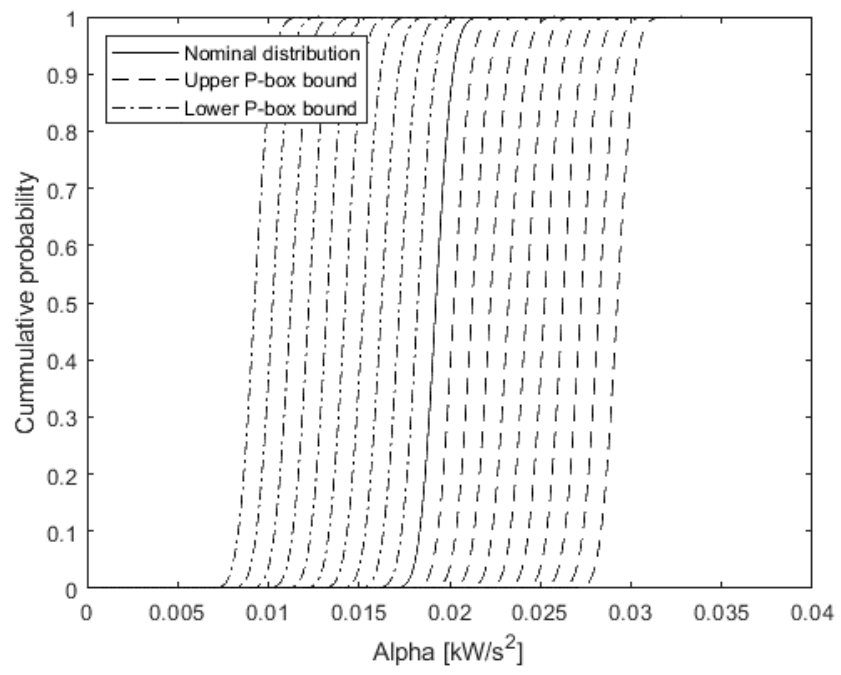

Figure 13. Simple application of info-gap to generate fire growth rate P-boxes

This outcome would provide the designers of the building with an understanding of the robustness that can be expected from the compartment, which can then be extrapolated to the whole building. Although the result for robustness is accompanied by a notion of likelihood or chance, it is important to understand that info-gap analysis mainly focuses on the potential for the system to resist a load, rather than on the likelihood of said load actually occurring.

The application of info-gap theory and the robustness function in this example is simplified to provide the reader with a clear understanding of the potential for its use in fire safety. As complexity increases, info-gap robustness measurement allows evaluating two competing design alternatives which could imply significantly different tradeoff in a fire safety strategy within a building. Such an evaluation is objective and is not based on the likelihood of an unknown event or condition, but on the amount of uncertainty that the system can tolerate and still perform adequately.

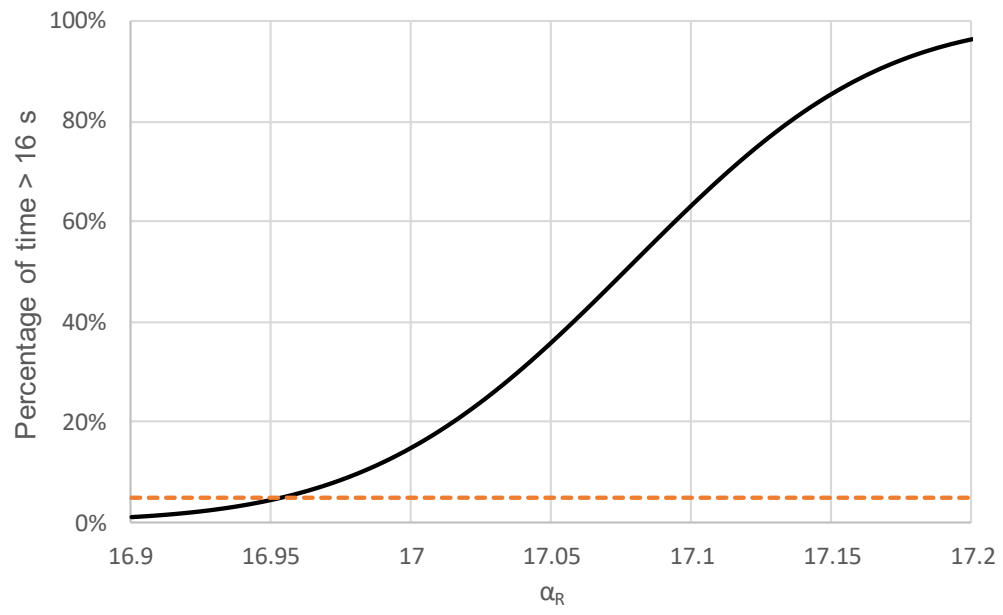

Figure 14. Likelihood of time descending to $2 \mathrm{~m}$ being less than 16 seconds; $5 \%$ chance at a value of $\alpha_{R}=16.95$

\subsection{Strength of knowledge (SoK)}

This alternative is applied to the compartment fire example, which begins by defining the levels and criteria for the strength of knowledge and output sensitivity. The former is adapted from previous work, as strength of knowledge criteria is largely compatible with the features of this example. For output sensitivity, the criteria are defined based 
on the variable of interest, i.e. the time for the smoke layer to descend to 2 meters height, compared to the time required for occupants to egress the compartment, which is 16 seconds based on the calculation of the previous section. The criteria for both aspects are presented in Table 6 and are applied to judge the list of assumptions within the analysis. The six assumptions and their SoK assessment are presented in Table 7, from which a wide range of potential issues are identified with the analysis.

Table 6. Strength of knowledge and output sensitivity levels and criteria

\begin{tabular}{|l|l|l|}
\hline Aspect & Level & Criteria \\
\hline \multirow{5}{*}{$\begin{array}{l}\text { Strength of } \\
\text { knowledge }\end{array}$} & High & $\begin{array}{l}\text {-Updated references back up the values or assumptions } \\
\text {-Strong and relevant theoretical grounds } \\
\text {-Subjective knowledge is backed up by theory or robust research }\end{array}$ \\
\cline { 2 - 3 } & Ledium & Neither high nor low \\
\cline { 2 - 3 } & Low & $\begin{array}{l}\text {-Poor theoretical grounds and references for the values and assumptions } \\
\text {-Low consensus between personnel involved in the assessment } \\
\text {-Knowledge sources are subjective and not validated }\end{array}$ \\
\hline \multirow{5}{*}{ Output sensitivity } & High & Variations within known ranges yield shorter available times than those required \\
\cline { 2 - 3 } & Medium & Neither high nor low \\
\cline { 2 - 3 } & Low & $\begin{array}{l}\text { Large-unrealistic- variations required to yield shorter available times than those } \\
\text { required }\end{array}$ \\
\hline
\end{tabular}

From the list, all assumptions have the potential to influence the result, but those with lowest SoK and highest output sensitivity (OS) can be prioritized. This makes assumptions 3, 5 and 6 stand out and require a close analysis. Assumption 3 questions the validity of the chosen un-tenability criterion selected as a function of smoke height layer. This potential issue with the performance criterion itself is treated by analyzing the output of the compartment fire model used (Annex I) and comparing both criteria.

The outcomes of the comparison are provided in Figure 15, showing that smoke height layer is a more conservative criterion. Based on this result, the SoK and OS are assigned new values (High, Low) and is no longer a pressing concern for the output of the analysis. The remaining two assumptions, No. 5 and 6, point towards unreliable inputs that can be addressed in a simple and effective manner. Assumption 5 points out that no detection, notification and premovement times are considered for the value of 16 seconds representing the required safe egress time. A premovement time that cannot be exactly pre-defined. A change in occupants condition (e.g. from awake and alert to asleep) could translate to lack of recognition of the fire and detection times in the range of several minutes. This could also be the case if the flaming fire was preceded by a previous smoldering phase where toxic gases are released. In conclusion, both assumptions remain unchanged and constitute an important source of uncertainty which can increase the previously calculated 16 seconds, to times of 46 seconds or more (using a pre-movement time of 30 seconds based on the SFPE Handbook data [124]).

As pre-movement time increases due to lack of adequate means of notification or lack of understanding of the occupants due to low familiarity, the system reaches an unacceptable performance with lower fire growth rates. This evidently echoes the robustness approach of the info-gap theory, but also implies a much simpler course of action. Despite the lack of quantification, here it is easy to identify it is essential to ensure proper notification and a delivery of clear instructions to the occupants in order to maintain the system's performance.

Table 7. List of assumption and SoK judgements

\begin{tabular}{|l|l|l|l|}
\hline Assumption & SoK & OS & Justification \\
\hline $\begin{array}{l}\text { 1. Fuel is polyurethane } \\
\text { foam }\end{array}$ & Medium & Medium & Representative of the fuel in a typical dwelling \\
\hline $\begin{array}{l}\text { 2. Alpha t-squared fire } \\
\text { growth is valid }\end{array}$ & High & Medium & $\begin{array}{l}\text { Despite fire spread and growth having a complex behavior, in a } \\
\text { dwelling this assumption is reasonable as long as different scenarios } \\
\text { are analyzed }\end{array}$ \\
\hline $\begin{array}{l}\text { 3. Smoke layer height } \\
\text { criterion is valid }\end{array}$ & $\begin{array}{l}\text { Low } \\
\text { (High) }\end{array}$ & $\begin{array}{l}\text { High } \\
\text { (Medium) }\end{array}$ & $\begin{array}{l}\text { Smoke layer temperature could reach a critical temperature before } \\
\text { the smoke descends to } 2 \text { m height, thus yielding untenable } \\
\text { conditions before it }\end{array}$ \\
\hline
\end{tabular}




\begin{tabular}{|l|l|l|l|}
\hline Assumption & SoK & OS & Justification \\
\hline $\begin{array}{l}\text { 4. No ventilation effect on } \\
\text { smoke layer descent }\end{array}$ & High & High & $\begin{array}{l}\text { Natural ventilation like doors and windows have a soffit below } 2 \mathrm{~m}, \\
\text { therefore assuming it does not influence the smoke layer descent is } \\
\text { onerous but valid for an initial analysis }\end{array}$ \\
\hline $\begin{array}{l}\text { 5. Detection, notification } \\
\text { and pre-movement times }= \\
0 \mathrm{~s}\end{array}$ & Low & High & $\begin{array}{l}\text { The occupants will react to the fire within the compartment and } \\
\text { immediately evacuate }\end{array}$ \\
\hline $\begin{array}{l}\text { 6. Walking speed }=0.75 \\
\mathrm{~m} / \mathrm{s}\end{array}$ & Medium & High & $\begin{array}{l}\text { Based on SFPE data [124] this is a slow speed, providing an onerous } \\
\text { scenario for this simple analysis }\end{array}$ \\
\hline
\end{tabular}
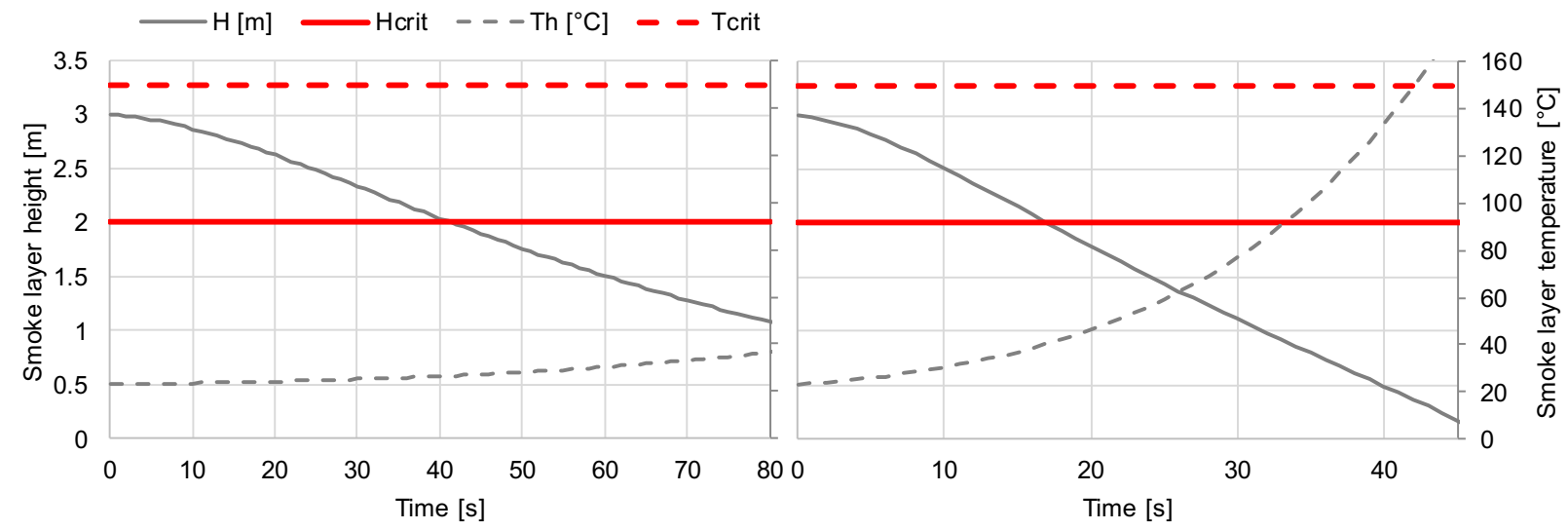

Figure 15. Comparison of tenability criteria for a slow (left) and ultra-fast (right) fire growth

\section{Alternatives evaluation}

The previous section presented a description of the main uncertainty analysis options, including a brief description. In this section an analysis of these alternatives is provided, which aims at helping risk analysis to select one of them according to their needs. To conduct the evaluation, the main steps of the Design Science Research Methodology (DSRM) [125] are adopted (Table 8).

Table 8. DSRM steps applied to this work

\begin{tabular}{|l|l|}
\hline DSRM step & Application to this work \\
\hline $\begin{array}{l}\text { Identify the problem and } \\
\text { motivate }\end{array}$ & $\begin{array}{l}\text { Better risk understanding through the use of appropriate uncertainty analysis options } \\
\text { (Section 1) }\end{array}$ \\
\hline Objectives of a solution & Provide a clear picture of the uncertainty analysis alternative for fire safety engineers \\
\hline Evaluation of alternatives & Use of hierarchy structure to perform the evaluation (Figure 16) \\
\hline Demonstration & Example of the compartment fire applied to the alternatives \\
\hline Communication & Conclusions and opportunities based on the analysis are presented (section 0) \\
\hline
\end{tabular}

This section addresses the evaluation of alternatives, for which a hierarchical structure is proposed following Prat's guidelines [126]. The two dimensions selected for evaluation are suitability and effectiveness in the context of a fire risk assessment. These dimensions are broken down into evaluation criteria and sub criteria as shown in Figure 16. The dimensions chosen reflect the main challenges of analyzing uncertainty in FSE. Understanding the added value of each alternative as well as its limitations is the first challenge, without regards for the technical difficulties of its implementation. This is covered in the first dimension, suitability. Despite the advantages of a particular approach, it could still require complex tools or steps to actually be implemented. This is a major challenge, as risk assessments are often done bounded by time and capital constrains. This is captured by the second dimension, effectiveness. The evaluation criteria for both dimensions are defined in Table 9. 


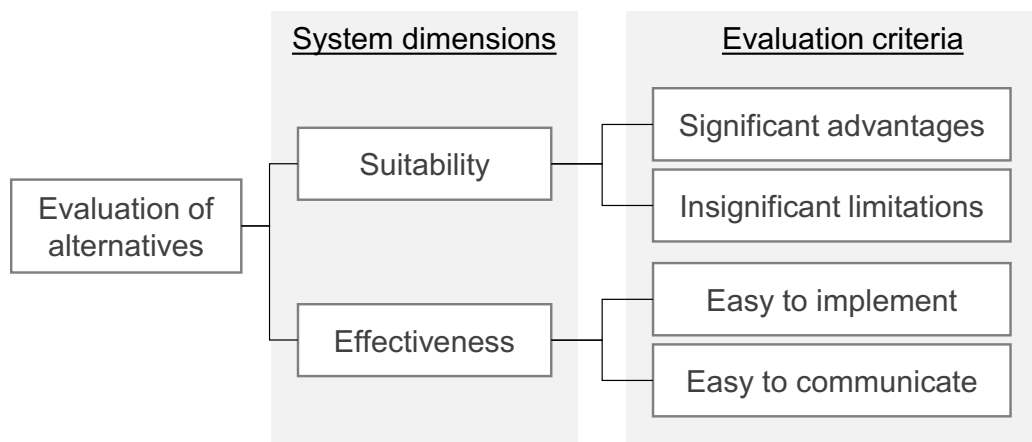

Figure 16. Proposed hierarchy structure for the evaluation of alternatives; based on [126]

Table 9. Evaluation criteria-Suitability dimension

\begin{tabular}{|l|l|l|}
\hline Evaluation criteria & \multicolumn{1}{|c|}{ Level } & \multicolumn{1}{c|}{ Indicator of level attainment } \\
\hline \multirow{4}{*}{$\begin{array}{l}\text { Significant } \\
\text { advantages }\end{array}$} & Fully achieved (FA) & $\begin{array}{l}\text { The alternative is advantageous relative to the knowledge it provides and } \\
\text { the potential to act upon it by relevant stakeholders. }\end{array}$ \\
\cline { 2 - 3 } & Partially achieved (PA) & Cannot be judged as FA nor NA \\
\cline { 2 - 3 } $\begin{array}{l}\text { Insignificant } \\
\text { limitations (not } \\
\text { related to } \\
\text { implementation) }\end{array}$ & Not achieved (NA) & $\begin{array}{l}\text { Does not provide significant advantages or none can be associated to this } \\
\text { incertitude space }\end{array}$ \\
\cline { 2 - 3 } & Fully achieved (FA) & $\begin{array}{l}\text { Limitations exits but are clearly defined and minor changes in inputs or } \\
\text { model parameters or assumptions do not make the approach inviable }\end{array}$ \\
\cline { 2 - 3 } Easy to implement & Not achieved (NA) & $\begin{array}{l}\text { It is possible to trespass the applicability limits with minor variations to } \\
\text { inputs or changes to model parameters or assumptions }\end{array}$ \\
\cline { 2 - 3 } & Fully achieved (FA) & $\begin{array}{l}\text { Clear sequence of steps in which data manipulation is clear and traceable; } \\
\text { guidelines, algorithms and software are readily available }\end{array}$ \\
\cline { 2 - 3 } & Not achieved (NA) & $\begin{array}{l}\text { Lengthy and complex process with no clear guidelines for implementation. } \\
\text { Software is not available or scarce. }\end{array}$ \\
\hline \multirow{3}{*}{$\begin{array}{l}\text { Easy to } \\
\text { communicate }\end{array}$} & Fully achieved (FA) & $\begin{array}{l}\text { The output's uncertainty is easy to communicate and compare, being } \\
\text { consistent with the quantity and detail level of the inputs. }\end{array}$ \\
\cline { 2 - 3 } & Partially achieved (PA) & Cannot be judged as FA nor NA \\
\cline { 2 - 3 } & Not achieved (NA) & $\begin{array}{l}\text { The output does not clearly represent the uncertainty involved and can be } \\
\text { inconsistent with the nature of the inputs. }\end{array}$ \\
\hline
\end{tabular}

Once the evaluation is completed for all alternatives, the results can be synthesized as presented in Table 10. Notice that the objective of the evaluation is to show that none of the alternatives is perfect and all of them will imply important challenges for the practitioners implementing them either in FSE or other fields. It is also important to notice that the challenges that each alternative imply vary greatly in the dimension and criteria evaluated, which means that some of them will be better suited for some problems. The detailed results of the evaluation are presented in Annex II, which includes the associated supporting comments, available software and implementation examples.

First, a general analysis of the results is done, beginning with those of the suitability dimension. The previous point of all approaches being useful is reflected by the results of the significant advantages criterion, where all alternatives partially or fully achieve it. It can be observed that a breakpoint exist in the insignificant limitations criterion, which can be decisive for practitioners exploring new options. The first four approaches score a NA for this criterion, as all of them are constructed on the basis of strong and often not justifiable assumptions such as following a particular shape of probability distribution function or on the subjective estimates of experts which can seldom be directly validated.

Although both info-gap and strength of knowledge present some important limitations, the basis of these approaches are physical phenomena and the recognition of the incomplete or imperfect knowledge, respectively. 
Such basis provides practitioners with imperfect but useful approaches in which uncertainty is explicitly formulated. In the effectiveness dimension, it can be observed that the more recent and alternative approaches present larger issues of implementation and communication. This can be a major obstacle for their implementation in the FSE context, as development of competences to correctly implement the alternatives might be needed. Communication is also an issue, as both the competences of the practitioners' play a crucial role, as well as the willingness of the AHJ and other stakeholders to analyze uncertainty from a non-probabilistic approach.

Table 10. Evaluation summary

\begin{tabular}{|c|l|c|c|c|c|c|c|c|}
\hline Dimension & Criterion & Probability & P-boxes & Evidence & Possibility & Info-gap & SoK & EMA \\
\hline \multirow{2}{*}{ Suitability } & Significant advantages & FA & FA & PA & PA & FA & FA & FA \\
\cline { 2 - 8 } & Insignificant limitations & NA & NA & NA & NA & PA & PA & PA \\
\hline \multirow{2}{*}{ Effectiveness } & Easy to implement & FA & PA & PA & NA & NA & PA & PA \\
\cline { 2 - 8 } & Easy to communicate & PA & PA & PA & PA & PA & FA & NA \\
\hline
\end{tabular}

With the exception of software limitations that decrease the implementation ease for possibility theory and the opposite situation for probability, the first four approaches are considerably similar. Each one offers a unique way to understand the likelihood of an event occurring or of a condition existing, but approach the problem in a similar manner and therefore also offer similar challenges for practitioners. In particular, those different to probability have a heavy reliance on subjective estimates provided by more than one expert. This is reflected by the consistent NA level of achievement for the insignificant limitations criterion by all four approaches, which -again- does not render them useless, but impose significant challenges on the practitioners who wish to implement them. The mechanical nature of the calculations involved in these approaches can lead to believe that the results are trustworthy, but each individual problem should be treated on a case-by-case basis and the limitations explicitly stated. This treatment of the potential sources of uncertainty within the approach itself is seldom done, as the mechanical nature of the approaches usually leads practitioner to rely only on sensitivity analysis.

Info-gap and strength of knowledge approaches present two different ways to deal with uncertainty without necessarily using a probabilistic approach, however they are able to accommodate it. The results of the evaluation for the former indicate significant advantages for practitioners as it avoids dealing with uncertainty by focusing on measuring the robustness. In the case of a fire risk assessment this translates into understanding how much extra loads can a building take under fire condition before the objectives are compromised. However, there is not a standard way to do it and the available examples -although detailed and clear- need to be carefully extrapolated into each individual problem. Here lie the important limitations for this approach, as a deep analytical understanding of the problem is not always available in FSE; this triggers the use of methodologies as the one previously mentioned based on the concept of the maximum allowable damage [91]. This methodology acknowledges the presence of uncertainty in the risk assessment and triggers two simultaneous processes: assessing the system's performance as a function of the safety objectives and systematically record and judge the assumptions and limitations embedded in inputs, parameters and models employed.

The purpose of judging assumptions and limitations is not only to identify potential weaknesses of the assessment, but to identify actions that allow monitoring and controlling them during the life-cycle of the system. In the context of the ISO 31000 framework, this would be part of the risk treatment plan. The default tool to judge assumptions and limitations in the maximum allowable damage methodology is the strength of knowledge approach. The evaluation results for this approach can be regarded as the best of all, as it fully achieves significant advantages and ease of communication. The bibliography available on this approach show how the simple idea of SoK can be applied in both a qualitative or quantitative format and effectively support decision making even in situations where knowledge is recognized to be incomplete or imperfect; this represents a significant tool for fire risk assessments, 
where much is known but even more assumed. The challenges of this approach lie on the need to properly setting it up in a case-by-case basis and with the use of categories that can evoke the same issues of constructing a risk analysis matrix [127].

In the suitability dimension, only EMA fully achieves the significant advantages criteria given its explicit recognition of deep uncertainty and the treatment of a massive universe of possibilities in order to inform decision-makers. An approach like EMA and others belonging to Robust Decision Making (RDM) explore a wide range of possible futures based on a large scale exploration of variations of both conditions and solutions and both the theoretical construction of these futures and the complex relationships between variables involved represent a significant limitation. Even when implementation (rated $P A$ ) is supported by machine-learning or artificial intelligence, the complexity of these algorithms can be such to not allow traceability of the results or exploring the relationships between key variables. Furthermore, EMA does not fully achieve the criteria for effectiveness, as its implementation is still limited to complex problems which can be well characterized and populated with significant background information. Communicating EMA's outputs also poses a challenge, particularly for stakeholders used to a quantitative answer in the form of probabilities or frequencies. This approach can be considered at the extreme end of the possibilities to analyze uncertainty in fire safety risk assessments, and could be a powerful tool to assess the potential impact of fire safety policy changes such as proposed bans on specific materials.

In today's big data world, the acquisition and consolidation of large databases has promoted the implementation of machine-learning algorithms that can quickly and effectively provide an output in contrast to highly analytical and complex calculations. Fire safety is not the exception and currently there are documented efforts of implementing it to support decision-making in evacuation strategies based on a database of 569 building evacuations [128]. Machine-learning has also been applied to provide faster results when simulating fires by using traditional model outputs to train the algorithm [129]. Both examples highlight the potential of an alternative not directly addressed by this work, which in the future could be used to analyze demographic and construction data to identify construction clusters with fire safety deficiencies or population groups with particular fire safety challenges. However, the implementation of machine learning is conditioned to training data. In the context of a fire risk assessment, unique fire and building features and interactions pose a major challenge for its implementation. Attempts to apply machine-learning to fire consequence modelling in nuclear facilities [130] could set the basis for integrating such models in a risk assessment, although uncertainty description might still require using the alternatives presented in this work.

\section{Discussion on the practitioners' perspective}

As previously stated, the aim of the paper is to supply practitioners with a picture of the uncertainty analysis approaches and their evaluation based on ease of implementation/communication. In order to gauge and discuss the impact of the alternatives analysis an interview with two risk assessment experts were interviewed. The interviews do not intend to provide a statistical representation of the perception of all practitioners, but to incite the debate on key issues and needed changes in the role of risk assessments and their outputs in FSE. First the profile of the interviewees is presented, followed by the interview results and a brief discussion. Interviewee 1 (I1) has a doctorate in chemical engineering in the topic of systems theory applied to safety engineering, over 10 years of academic career in the process safety field and is currently a senior health and safety professional at a major oil \& gas company. Interviewee 2 (12) has a doctorate in civil engineering in the topic of structural fire, over 10 years of academic career in the FSE field and is currently a professor in a worldwide recognized university. Both interviewees were consulted due to the trajectories and recognition among peers of their contributions to their respective fields.

First, the interviewees were asked if they consider the probabilistic approach the best suited alternative to assess the performance of an engineering system, specifically the fire safety of an occupied building. 11 pointed out that identifying low probability scenarios is not always possible following a probabilistic approach, requiring complementary techniques. In particular, 11 drew attention to the outmost need of preliminary qualitative risk analysis that focus on identification of scenarios that then lead to refined quantitative analysis of prioritized scenarios. This is consistent with the approach presented by BS 7974:2019 [69], and differs from a more mechanistic 
approach as proposed by the verification methods [131]. I1 states that following a probabilistic approach or an alternative is a decision to be made as a function of the analysis objectives and the available resources. He further suggested such a decision needs to be made by stakeholders at an early stage of the project and that in particular, the probabilistic approach lacks usefulness when the reliability changes in the system (also in its sub-systems and elements) are not managed through time. 12 answer is that the probabilistic approach is the best suited alternative for some systems, as it is the alternative that provides the highest resolution, i.e. most insight in the spectrum of possible performance of the system in case of fire. Contrasting this, 12 recognizes that some systems might only need a site visit from a competent professional to effectively account for uncertainties. A key point made by both II and 12 is that a risk assessment cannot be turned into the probabilistic analysis of all involved variables or uncertainties. 12 reinforces this mentioning the value of guidance and of prescriptive codes, which are applicable -and adequatefor a large range of projects. 12 states that codes and guidance -particularly in FSE- have the value of providing a common benchmark and alternatives to approach different problems. This range can be seen as to go from a purely guidance based (prescriptive) to depending fully on the competence of the practitioners (performance-based). This last point made by 12 poses an interesting issue, as both extremes of practice range in FSE (rule-based and performance based) have identified the danger posed by poorly managed uncertainties. In the context of chemical process safety, risk assessment guidelines point towards the probabilistic approach and the use of Paté-Cornell's [80] uncertainty management levels to manage uncertainty in a quantitative manner. However, safety engineering presents a wide range of implicit and explicit manners to deal with uncertainty [43] including the way in which scenarios are identified, pre-defined rules for systems fitting a taxonomy (prescriptive approach), etc. The interviewees agreed on the need for a preceding qualitative assessment that guides the probabilistic one, and on the fact that using the former is no guarantee that uncertainty is adequately accounted for and managed.

The previous leads to the second question regarding the obstacles of implementing the alternatives in practice. II states that the alternatives constitute a 'toolbox', from which a selection must be made early in the assessment. This selection is based on three elements: 1) assessment objectives as a function of decision-making, 2) available information and 3) available resources. Given that these elements are clearly identified, 11 finds that any obstacle in selecting an alternative will be associated to the stakeholders with authorization (approval) power and the system users. This is coherent with the difficulties in implementation found in the evaluation, which are common to all alternatives and require informed stakeholders with the ability to interpret the outputs. Furthermore, 11 emphasizes the need to prioritize the uncertainty analysis alternatives for each assessment based on an initial qualitative analysis. To address the question, 12 states that in FSE the current preferred approach to risk assessments is implicit worst credible scenarios (deterministic), which is in fact backed up by the analysis of Johansson [132] of Australian fire engineering reports and presented in a broader international perspective by Bjelland [133]. Therefore, 12 highlights that practitioners should be more aware and willing to communicate about the uncertainties involved in deterministic assessments, as well as their limitations. However, 12 recognizes that the current construction focus on the end goal (i.e. getting a design approved and built) limits the possibility of communicating the uncertainties completely and effectively. This is consistent with the Shergold-Weir enquiry [38] in Australia and with the Hackitt [2] enquiry in the UK. The former reflects it with several recommendations, including No. 9 and 10 associated to the lack of transparency and the need for a code of conduct for building surveyors. The latter referred to the issues associated to the construction regulatory system failure stating that "the primary motivation is to do things as quickly and cheaply as possible rather than to deliver quality homes which are safe for people to live in". 12 concludes that the main obstacle in FSE to implement the presented alternatives and better support decision-making is the lack of openness about the effects of uncertainties (within risk assessments) on objectives.

\section{Conclusions}

This work has described the need to better understand and employ available options for uncertainty analysis in the context of a fire risk assessment, starting from the premise that a single approach is not enough to tackle current challenges for FSE. Given the variability of uncertainty sources and their nature, practitioners cannot force all of them into a single analysis alternative, despite the lack of appropriate guidelines to do so. The lack of a clear perspective on the available alternatives has been addressed by this work, describing them and applying them to a simple compartment fire problem. Applying the considered alternatives to a simple fire safety problem the results vary significantly and imply supporting different decisions for the compartment. Despite its simplicity, the example 
illustrates the variability of the outputs based on the uncertainty analysis alternative. More importantly, no alternative provides the 'right' answer, while each one provides different pieces of valuable information.

The advantages and challenges of each alternative in relation to their implementation and the outputs they provide for the decision-making process were judged following the modified DSRM methodology. Using the suitability and effectiveness dimensions, each one of the eight alternatives were evaluated in the context of FSE. The results indicate -as the case study- that no alternative is the 'best' and each one must be considered carefully in the context of the assessment being carried out. One common challenge is the reliance on mathematical calculations that are increasingly complex, requiring competent users capable of handling them or a robust software package that aids the calculations. As with any tool used in engineering, the use of available software must be done within its applicability range and considering the assumptions that the tool itself introduces to the calculation. A versatile alternative is found in the strength of knowledge, however the calibration of its categories could also pose challenges for its implementation, i.e. how to define a 'high' strength of knowledge.

The work presented aims at widening the perspective of practitioners fire safety engineers involved in risk assessment, but capitalizes on the knowledge and experience of different disciplines facing the same challenges. Recognizing that very distinct disciplines share challenges and solutions, create a needed synergy that may build new, more trustworthy and effective, risk assessments. This work capitalizes on the work done by many others throughout decades and expects to provide the basis for future work, in which technically challenging alternatives such as EMA can be efficiently implemented to typical problems in chemical process and fire safety engineering.

\section{Acknowledgements}

The authors recognize the participation of the two interviewees Dr Felipe Muñoz Giraldo from the Colombian National Oil Company (Ecopetrol S.A.) and Prof Ruben Van Coile from Ghent University, who despite time zone differences and bustling agendas found time to engage in invaluable discussions. Through the interviews, the authors understood the meaning of this work from different perspectives, allowing for refining and important adjustments. These conversations also reflect the wealth of knowledge each practitioner has when it comes to uncertainty accounting and therefore the large amount of work yet to be done to provide unified, useful guidelines for its accounting in risk assessments.

\section{References}

1. Jaime E. Cadena, F.M., The Link between Fire Research and Process Safety: An Evolution from Specific Needs to General Concern. Chemical Engineering Transactions, 2013. 31: p. 679-684.

2. Hackitt, J., Building a Safer Future, Independent Review of Building Regulations and Fire Safety: Final Report. 2018: London, UK.

3. Van Coile, R., G. Jomaas, and L. Bisby, Defining ALARP for fire safety engineering design via the Life Quality Index. Fire Safety Journal, 2019. 107: p. 1-14.

4. Gernay, T., et al., Efficient uncertainty quantification method applied to structural fire engineering computations. Engineering Structures, 2019. 183: p. 1-17.

5. Van Coile, R., et al., The Need for Hierarchies of Acceptance Criteria for Probabilistic Risk Assessments in Fire Engineering. Fire Technology, 2018.

6. Van Coile, R., et al., An Unbiased Method for Probabilistic Fire Safety Engineering, Requiring a Limited Number of Model Evaluations. Fire Technology, 2017. 53(5): p. 1705-1744.

7. Beard, A.N., Risk assessment assumptions. Civil Engineering and Environmental Systems, 2004. 21(1): p. 19-31.

8. Aven, T. and O. Renn, On risk defined as an event where the outcome is uncertain. Journal of Risk Research, 2009. 12(1): p. 1-11.

9. Analysis, C.o.F.o.R., Society for Risk Analysis Glossary. 2015, Society for Risk Analysis.

10. Standardization, I.O.f., ISO 31000:2018: Risk management - Principles and guidelines. 2018: Geneva, Switzerland. 
11. Aven, T., O. Renn, and E.A. Rosa, On the ontological status of the concept of risk. Safety Science, 2011. 49(8): p. 1074-1079.

12. Beck, M. and B. Kewell, Risk. 2012: WORLD SCIENTIFIC. 380.

13. Blokland, P. and G. Reniers, An Ontological and Semantic Foundation for Safety and Security Science. Sustainability, 2019. 11(21): p. 6024.

14. Usmani, A.S., Y.C. Chung, and J.L. Torero, How did the WTC towers collapse: a new theory. Fire Safety Journal, 2003. 38(6): p. 501-533.

15. Amadeo, K., How the 9/11 Attacks Affect the Economy Today, in The Balance. 2020: New York, USA.

16. Torero, J., Grenfell tower: Phase 1 report. 2018, Torero, Abecassis Empis and Cowlard.

17. Booth, R., Grenfell inquiry has cost 100 times amount saved on cladding, in The Guardian. 2019: London, UK.

18. Johnston, K., Inferno: the fire that brought a city to its knees, in New Zealand Herald. 2019: Auckland, New Zealand.

19. Chris Vedelago, S.I., Company behind Campbellfield fire collapses, taxpayers could foot bill, in The Age. 2019: Melbourne, Australia.

20. India, P.T.o., 81 killed as massive fire spreads quick through chemical warehouses in Dhaka. 2019.

21. Dionne, G., Risk Management: History, Definition, and Critique. Risk Management and Insurance Review, 2013. 16(2): p. 147-166.

22. Talja, H., et al., Structural safety analysis with engineering integrity assessment tools. Computers \& Structures, 1997. 64(1): p. 759-770.

23. Wang, X., et al., Comparison of the reliability-based and safety factor methods for structural design. Applied Mathematical Modelling, 2019. 72: p. 68-84.

24. Aven, T., Risk assessment and risk management: Review of recent advances on their foundation. European Journal of Operational Research, 2016. 253(1): p. 1-13.

25. Årstad, I. and T. Aven, Managing major accident risk: Concerns about complacency and complexity in practice. Safety Science, 2017. 91: p. 114-121.

26. Goerlandt, F. and G. Reniers, Prediction in a risk analysis context: Implications for selecting a risk perspective in practical applications. Safety Science, 2018. 101: p. 344-351.

27. Aven, T., On the Need for Restricting the Probabilistic Analysis in Risk Assessments to Variability. Risk Analysis, 2010. 30(3): p. 354-360.

28. Zeng, Z. and E. Zio, A classification-based framework for trustworthiness assessment of quantitative risk analysis. Safety Science, 2017. 99: p. 215-226.

29. Pasman, H. and W. Rogers, How trustworthy are risk assessment results, and what can be done about the uncertainties they are plagued with? Journal of Loss Prevention in the Process Industries, 2018. 55: p. 162177.

30. Tixier, J., et al., Review of 62 risk analysis methodologies of industrial plants. Journal of Loss Prevention in the Process Industries, 2002. 15(4): p. 291-303.

31. Marhavilas, P.K., D. Koulouriotis, and V. Gemeni, Risk analysis and assessment methodologies in the work sites: On a review, classification and comparative study of the scientific literature of the period 2000-2009. Journal of Loss Prevention in the Process Industries, 2011. 24(5): p. 477-523.

32. Baecher, G., Uncertainty in dam safety risk analysis. Vol. 10. 2016. 1-17.

33. Yang, X., S. Haugen, and N. Paltrinieri, Clarifying the concept of operational risk assessment in the oil and gas industry. Safety Science, 2018. 108: p. 259-268.

34. Aven, T. and V. Kristensen, How the distinction between general knowledge and specific knowledge can improve the foundation and practice of risk assessment and risk-informed decision-making. Reliability Engineering \& System Safety, 2019. 191: p. 106553.

35. Meacham, B.J. Concepts of a Performance-based Building Regulatory System for the United States. in International Association for Fire Safety Science. Fire Safety Science. Proceedings. Fifth (5th) International Symposium. 1997. Melbourne, Australia.

36. Ministry of Housing, C.L.G., Structure: Approved Document A, in The Building Regulations 2010, H. Government, Editor. 20109: London, UK.

37. Bisby, L., 'Adequacy' in structural fire engineering, in Technical Lecture Series 2019. 2019, The Institution of Structural Engineers (IStructE). 
38. Peter Shergold, B.W., Building Confidence - Improving the effectiveness of compliance and enforcement systems for the building and construction industry across Australia. 2018, Building Ministers' Forum (BMF).

39. genco, G., Municipal Building Surveyor report - Lacrosse Building Fire. 2015, City of Melbourne: Melbourne, Australia.

40. Cooke, R. and T. Bedford, What is uncertainty?, in Probabilistic Risk Analysis: Foundations and Methods. 2001, Cambridge University Press: Cambridge. p. 17-38.

41. Hayes, K.R., Uncertainty and uncertainty analysis methods. 2011, CSIRO: Tasmania, Australia.

42. Walker, W.E., R.J. Lempert, and J.H. Kwakkel, Deep Uncertainty, in Encyclopedia of Operations Research and Management Science, S.I. Gass and M.C. Fu, Editors. 2013, Springer US: Boston, MA. p. 395-402.

43. Notarianni, K.A. and G.W. Parry, Uncertainty, in SFPE Handbook of Fire Protection Engineering, M.J. Hurley, et al., Editors. 2016, Springer New York: New York, NY. p. 2992-3047.

44. Kaplan, S. and B.J. Garrick, On The Quantitative Definition of Risk. Risk Analysis, 1981. 1(1): p. 11-27.

45. Zio, E. and N. Pedroni, Uncertainty characterization in risk analysis for decision-making practice. 2012.

46. Colyvan, M., Is Probability the Only Coherent Approach to Uncertainty? Risk Analysis, 2008. 28(3): p. 645652.

47. Meacham, B.J. and I.J. Van Straalen, A socio-technical system framework for risk-informed performancebased building regulation. Building Research \&amp; Information, 2018. 46(4): p. 444-462.

48. Johansen, I.L. and M. Rausand, Ambiguity in risk assessment. Safety Science, 2015. 80: p. 243-251.

49. Notarianni, K.A. and G.W. Parry, SFPE Handbook of Fire Protection Engineering, Fifth Edition. 2016: Springer New York. 2992-3047.

50. Hurley, M., Uncertainty in Fire Protection Engineering Design. Journal of Testing and Evaluation, 2012. 40(1): p. 12-17.

51. Kaplan, S., Y.Y. Haimes, and B.J. Garrick, Fitting Hierarchical Holographic Modeling into the Theory of Scenario Structuring and a Resulting Refinement to the Quantitative Definition of Risk. Risk Analysis, 2001. 21(5): p. 807-807.

52. Aven, T., Selective critique of risk assessments with recommendations for improving methodology and practise. Reliability Engineering \& System Safety, 2011. 96(5): p. 509-514.

53. Commission, U.S.N.R., Reactor Safety Study: An Assessment of Accident Risks in U.S. Commercial Nuclear Power Plants. 1975.

54. Benintendi, R., Chapter 12 - Quantitative Risk Assessment, in Process Safety Calculations. 2018, Elsevier. p. 607-628.

55. Quantitative Risk Analysis, in Handbook of Safety Principles.

56. Ramachandran, G. and D.A. Charters, Quantitative risk assessment in fire safety Ganapathy Ramachandran and David A. Charters, ed. C. Ebooks. 2011, London ; New York: London ; New York : Spon Press.

57. Safety, A.I.o.C.E.C.f.C.P., Guidelines for chemical process quantitative risk analysis. 2000: The Center.

58. lervolino, I., et al., Quantitative risk analysis for the Amerigo Vespucci (Florence, Italy) airport including domino effects. Safety Science, 2019. 113: p. 472-489.

59. Zhao, J., et al., Quantitative risk assessment of continuous liquid spill fires based on spread and burning behaviours. Applied Thermal Engineering, 2017. 126: p. 500-506.

60. Antonioni, G., et al., Quantitative assessment of risk due to NaTech scenarios caused by floods. Reliability Engineering \& System Safety, 2015. 142: p. 334-345.

61. Cozzani, V., et al., Quantitative assessment of domino and NaTech scenarios in complex industrial areas. Journal of Loss Prevention in the Process Industries, 2014. 28: p. 10-22.

62. Gye, H.-R., et al., Quantitative risk assessment of an urban hydrogen refueling station. International Journal of Hydrogen Energy, 2019. 44(2): p. 1288-1298.

63. Ltd, G.P., Report for Boodarie Strategic Industrial Area-Concept Plan Quantitative Risk Assessment. 2012.

64. Vanorio, G. and J. Mera, Methodology for risk analysis in railway tunnels using Monte Carlo simulation. 2012. 673-683.

65. Meng, Q., et al., QRA Model-Based Risk Impact Analysis of Traffic Flow in Urban Road Tunnels. Risk Analysis, 2011. 31(12): p. 1872-1882. 
66. Amundrud, $\varnothing$. and T. Aven, On how to understand and acknowledge risk. Reliability Engineering \& System Safety, 2015. 142: p. 42-47.

67. Zio, E., The future of risk assessment. Reliability Engineering \& System Safety, 2018. 177: p. 176-190.

68. Rausand, M. and K. Øien, The basic concepts of failure analysis. Reliability Engineering \& System Safety, 1996. 53(1): p. 73-83.

69. (BSI), B.S.I., BS 7974:2019, Application of fire safety engineering principles to the design of buildings - Code of practice. 2019: BSI.

70. Goerlandt, F., N. Khakzad, and G. Reniers, Validity and validation of safety-related quantitative risk analysis: A review. Safety Science, 2016.

71. A. Rae, J.M., R. Alexander, The Science and Superstition of Quantitative Risk Assessment, in Proceedings of PSAM 11 \& ESREL 2012. 2012, International Association of Probabilistic Safety Assessment and Management, IAPSAM. p. 2292-2301.

72. Goerlandt, F. and G. Reniers, Evidence assessment schemes for semi-quantitative risk analyses: A response to Roger Flage and Terje Aven. Safety Science, 2017. 98: p. 12-16.

73. Bjørnsen, K., J.T. Selvik, and T. Aven, A semi-quantitative assessment process for improved use of the expected value of information measure in safety management. Reliability Engineering \& System Safety, 2019. 188: p. 494-502.

74. Flage, R. and T. Aven, Some brief concluding remarks in relation to the discussion with Floris Goerlandt and Genserik Reniers about strength of knowledge (strength of evidence) judgments in semi-quantitative risk analysis. Safety Science, 2018. 108: p. 237.

75. Khorsandi, J. and T. Aven, Incorporating Assumption Deviation Risk in Quantitative Risk Assessments: A Semi-Quantitative Approach. Vol. 163. 2017.

76. Askeland, T., R. Flage, and T. Aven, Moving beyond probabilities - Strength of knowledge characterisations applied to security. Reliability Engineering \& System Safety, 2017. 159: p. 196-205.

77. Bjerga, T., T. Aven, and E. Zio, Uncertainty treatment in risk analysis of complex systems: The cases of STAMP and FRAM. Reliability Engineering \& System Safety, 2016. 156: p. 203-209.

78. Aven, T., Supplementing quantitative risk assessments with a stage addressing the risk understanding of the decision maker. Reliability Engineering \& System Safety, 2016. 152: p. 51-57.

79. Castino, G., Fire Risk Assessment. 1982: ASTM International.

80. Paté-Cornell, M.E., Uncertainties in risk analysis: Six levels of treatment. Reliability Engineering \& System Safety, 1996. 54(2): p. 95-111.

81. Flage, R., et al., Concerns, Challenges, and Directions of Development for the Issue of Representing Uncertainty in Risk Assessment. Risk Analysis, 2014. 34(7): p. 1196-1207.

82. Dubois, D., Representation, Propagation, and Decision Issues in Risk Analysis Under Incomplete Probabilistic Information. Risk Analysis, 2010. 30(3): p. 361-368.

83. Klir, G.J., Generalized information theory: aims, results, and open problems. Reliability Engineering \& System Safety, 2004. 85(1): p. 21-38.

84. Beer, M., S. Ferson, and V. Kreinovich, Imprecise probabilities in engineering analyses. Mechanical Systems and Signal Processing, 2013. 37(1): p. 4-29.

85. Aven, T., A risk concept applicable for both probabilistic and non-probabilistic perspectives. Safety Science, 2011. 49(8): p. 1080-1086.

86. Abdo, H., J.M. Flaus, and F. Masse, Uncertainty quantification in risk assessment - Representation, propagation and treatment approaches: Application to atmospheric dispersion modeling. Journal of Loss Prevention in the Process Industries, 2017. 49: p. 551-571.

87. Lempert, R.J., Robust Decision Making (RDM), in Decision Making under Deep Uncertainty: From Theory to Practice, V.A.W.J. Marchau, et al., Editors. 2019, Springer International Publishing: Cham. p. 23-51.

88. Y. Ben-Haim, Y.M., Info-gap Decision Theory For Engineering Design. Or: Why 'Good' is Preferable to 'Best', in Engineering Design Reliability Handbook, D.G.a.S.S. E. Nikolaides, Editor. 2005, CRC Press.

89. Bankes, S., Exploratory Modeling for Policy Analysis. Operations Research, 1993. 41: p. 435-449.

90. Takewaki, I. and Y. Ben-Haim, Info-gap robust design with load and model uncertainties. Journal of Sound and Vibration, 2005. 288(3): p. 551-570.

91. J. Cadena, J.H., C. Maluk, D. Lange, J. L. Torero, A. F. Osorio, Overcoming Risk Assessment Limitations for Potential Fires in a Multi-Occupancy Building. Chemical Engineering Transactions, 2019. 77. 
92. Kabir, S. and Y. Papadopoulos, A review of applications of fuzzy sets to safety and reliability engineering. International Journal of Approximate Reasoning, 2018. 100.

93. Shi, H. A Fuzzy Approach to Building Fire Risk Assessment and Analysis. in 2009 Third International Symposium on Intelligent Information Technology Application. 2009.

94. Funtowicz, S.O., Uncertainty and quality in science for policy / by Silvio O. Funtowicz and Jerome R. Ravetz. Theory and decision library. Series A, Philosophy and methodology of the social sciences ; v. 15., ed. J.R. Ravetz. 1990, Dordrecht, the Netherlands ; Norwell, MA, U.S.A: Kluwer Academic Publishers.

95. Ellis, E.C., et al., LONG-TERM CHANGE IN VILLAGE-SCALE ECOSYSTEMS IN CHINA USING LANDSCAPE AND STATISTICAL METHODS. Ecological Applications, 2000. 10(4): p. 1057-1073.

96. Zadeh, L.A., A Note on Z-numbers. Information Sciences, 2011. 181(14): p. 2923-2932.

97. Young, C., Model Uncertainty and the Crisis in Science. Socius, 2018. 4: p. 2378023117737206.

98. HSE, Offshore Hydrocarbon Release Statistics 2001, in HID Statistics Report HSR. 2001, Health \& Safety Executive.

99. Frank, M.V., Probabilistic Analysis of the Inadvertent Reentry of the Cassini Spacecraft's Radioisotope Thermoelectric Generators. Risk Analysis, 2000. 20(2): p. 251-260.

100. Laboratory, J.P., Cassini Earth Swingby Plan Supplement. 1997, Jet Propulsion Laboratory: Pasadena, CA, USA.

101. Apostolakis, G., The Concept of Probability if Safety Assessments of Technological Systems. Science (New York, N.Y.), 1991. 250: p. 1359-64.

102. Savage, L.J., The foundations of statistics. 2nd. rev. ed.. ed. 1972, New York: Dover Publications.

103. Barua, S., et al., Bayesian network based dynamic operational risk assessment. Journal of Loss Prevention in the Process Industries, 2016. 41: p. 399-410.

104. Hanea, D. and B. Ale, Risk of human fatality in building fires: A decision tool using Bayesian networks. Fire Safety Journal, 2009. 44(5): p. 704-710.

105. Traub, J.F., Interval Analysis. Science, 1967. 158(3799): p. 365-365.

106. Du, X. Uncertainty Analysis With Probability and Evidence Theories. in ASME 2006 International Design Engineering Technical Conferences and Computers and Information in Engineering Conference. 2006.

107. Dell'Orco, M. and S. Kikuchi, An alternative approach for choice models in transportation: Use of possibility theory for comparison of utilities. Yugoslav Journal of Operations Research, 2004. 14.

108. Darby, J.L., Estimating Terrorist Risk with Possibility Theory. 2004.

109. Ouazraoui, N., et al., Layers of protection analysis in the framework of possibility theory. Journal of Hazardous Materials, 2013. 262: p. 168-178.

110. Mandal, S. and J. Maiti, Risk analysis using FMEA: Fuzzy similarity value and possibility theory based approach. Expert Systems with Applications, 2014. 41(7): p. 3527-3537.

111. Ben-Haim, Y., Value-at-risk with info-gap uncertainty. The Journal of Risk Finance Incorporating Balance Sheet, 2005. 6(5): p. 388-403.

112. Aven, T., Knowledge in Risk Assessment and Management Fundamental Ideas, Principles and Approaches. 2017: p. 143-164.

113. Kwakkel, J.H., The Exploratory Modeling Workbench: An open source toolkit for exploratory modeling, scenario discovery, and (multi-objective) robust decision making. Environmental Modelling \& Software, 2017. 96: p. 239-250.

114. D. Groves, E.B., J. R. Fischbach, D. Knopman, Adapting to a Changing Colorado River: Making Future Water Deliveries More Reliable Through Robust Management Strategies, in American Geophysical Union, Fall Meeting 2013. 2013.

115. Ocran, N., Fire loads and design fires for mid-rise buildings. 2012, Carleton University.

116. Bwalya, A., N. Benichou, and M. Sultan, Literature Review on Design Fires. 2003.

117. M. Nilsson, N.J., P. Van Hees, A New Method for Quantifying Fire Growth Rates Using Statistical and Empirical Data - Applied to Determine the Effect of Arson Fire Safety Science-Proceedings of the Eleventh International Symposium, 2014: p. 517-530.

118. Sam L. Savage, M.T., SIP Math. 2012.

119. (NCD-RisC), N.R.F.C. Height: Evolution of adult height over time. 2020 13/08/2020]; Available from: http://www.ncdrisc.org/height-mean-distribution.html. 
120. Hopkin, C., et al., Design Fire Characteristics for Probabilistic Assessments of Dwellings in England. Fire Technology, 2019.

121. Yildiz, A.E., I. Dikmen, and M.T. Birgonul, Using Expert Opinion for Risk Assessment: A Case Study of a Construction Project Utilizing a Risk Mapping Tool. Procedia - Social and Behavioral Sciences, 2014. 119: $p$. 519-528.

122. Bergmans, H., et al., Working with Scenarios, Risk Assessment and Capabilities in the National Safety and Security Strategy of the Netherlands. 2009.

123. Ferson, S. and W.T. Tucker. Probability boxes as info-gap models. in NAFIPS 2008 - 2008 Annual Meeting of the North American Fuzzy Information Processing Society. 2008.

124. Gwynne, S.M.V. and K.E. Boyce, Engineering Data, in SFPE Handbook of Fire Protection Engineering, M.J. Hurley, et al., Editors. 2016, Springer New York: New York, NY. p. 2429-2551.

125. Peffers, K., et al., A design science research methodology for information systems research. Vol. 24.2007. 45-77.

126. Prat, N., I. Wattiau, and J. Akoka, Artifact Evaluation in Information Systems Design Science Research ? A Holistic View. 2014.

127. Duijm, N.J., Recommendations on the use and design of risk matrices. Safety Science, 2015. 76: p. $21-31$.

128. Zhao, X., R. Lovreglio, and D. Nilsson, Modelling and interpreting pre-evacuation decision-making using machine learning. Automation in Construction, 2020. 113: p. 103140.

129. Lattimer, B.Y., J.L. Hodges, and A.M. Lattimer, Using machine learning in physics-based simulation of fire. Fire Safety Journal, 2020. 114: p. 102991.

130. Worrell, C., et al., Machine learning of fire hazard model simulations for use in probabilistic safety assessments at nuclear power plants. Reliability Engineering \& System Safety, 2019. 183: p. 128-142.

131. Johnson, P. and N. Lobel, Fire Safety Verification Method - The Australia Research Experience. Journal of Physics: Conference Series, 2018. 1107: p. 042033.

132. Johansson, U., B. Stratton, and P. Olsson, On the Current Quality and Depth of Fire Safety Engineering Analysis in Australia - A Statistical Review of Recent Designs. 2011.

133. Bjelland, $\mathrm{H}$. and A. Borg, On the use of scenario analysis in combination with prescriptive fire safety design requirements. Environment Systems \& Decisions, 2013. 33(1): p. 33-42.

134. Denœux, T., Inner and Outer Approximation of Belief Structures Using a Hierarchical Clustering Approach. International Journal of Uncertainty, Fuzziness and Knowledge-Based Systems, 2001. 9: p. 437-460.

135. Guyonnet, D., et al., Hybrid Approach for Addressing Uncertainty in Risk Assessments. Journal of Environmental Engineering, 2003. 129(1): p. 68-78.

\section{Annex I-Compartment fire model}

The model for the compartment fire begins defining the heat release rate of the burning fuel, which is given by:

$$
\text { Heat Release Rate }=\dot{Q}=\Delta H_{c} \cdot \dot{m}_{f}
$$

$\dot{Q}$ is the heat release rate of a material -and this is measured in Watts (W), $\Delta H_{c}$ is the ideal heat of combustion of the fuel measured in $[\mathrm{J} / \mathrm{kg}]$ and $\dot{m}_{f}$ is the burning rate measured in $[\mathrm{kg} / \mathrm{s}]$. The latter can also be computed as a function of the area by defining is as:

$$
\dot{m}_{f}=A \cdot \dot{m}_{f}^{\prime \prime}
$$

Where $\mathrm{A}$ is the area of the fire and $\dot{m}_{f}{ }^{\prime \prime}$ is the burning rate per unit area. The fire growth can be extremely complex to model due to solid fuel combustion processes. A key -but onerous- simplification is that a fire can grow radially at an exponential rate. This means that the area of the fire can be described as a function of a radial fire $\operatorname{spread}\left(v_{s}\right)$ :

$$
A=\pi r^{2}=\pi\left(v_{s} \cdot t\right)^{2}
$$

Where $t$ is the time step. Integrating these three equations the heat release rate can be expressed as a function of a fire growth rate parameter known as alpha $(\alpha)$ : 


$$
\dot{Q}=\left(\Delta H_{c} \cdot \pi \cdot v_{s}^{2} \cdot \dot{m}_{f}^{\prime \prime}\right) \cdot t^{2}=\alpha t^{2}
$$

Performing an energy balance based on the heat released by the fire and the heat transferred by radiation to the surroundings (taken as a $30 \%$ of the total released), the heat feedback into the fire and the heat transferred to the smoke, it can be found that the smoke temperature can be expressed as:

$$
T_{S}=T_{A}+\frac{\dot{Q}_{s}}{\dot{m}_{A} C_{p}}
$$

With $\dot{m}_{A}$ the air entrainment is produced by the fire and the smoke plume, $C_{p}$ is the specific heat capacity of the smoke, $T_{S}$ is the temperature of the smoke, and $T_{A}$ is the temperature of the ambient air. Based on experimental correlations, the air entrainment can be estimated as:

$$
\dot{m}_{A}=E\left(\frac{g \rho_{A}^{2}}{C_{p} T_{A}}\right)^{1 / 3} \dot{Q}^{1 / 3} H^{5 / 3}
$$

With g the gravity of the earth, $\mathrm{E}$ the entrainment constant (taken as 0.2 ), $\rho_{A}$ the air's density and $\mathrm{H}$ the height at which the air entrainment is estimated. Assuming that the smoke produced is the same as air is entrained, it is possible to find the height of the smoke layer if its density is known $\left(\rho_{S}\right)$. To estimate it, the ideal gas law is used:

$$
\rho_{S}=\rho_{A} \frac{T_{A}}{T_{S}}
$$

Using the compartment's ceiling area and the volume of the smoke layer, its height can be calculated:

$$
H_{S}=\frac{V_{S}}{A_{\text {Ceiling }}}=\frac{\dot{m}_{S} / \rho_{S}}{A_{\text {Ceiling }}}
$$

\begin{tabular}{|c|c|c|c|}
\hline Dimension & Criterion & Evaluation & Supporting comments \\
\hline & $\begin{array}{l}\text { Significant } \\
\text { advantages }\end{array}$ & FA & $\begin{array}{l}\text { The main strength of this approach is that it considers a range of possible } \\
\text { values for a quantity of interest and distributes the probability along it. } \\
\text { This allows fitting a distribution that best fits the experimental data and } \\
\text { obtaining its parameters, which allow for future estimations of the 'a } \\
\text { posteriori' probability of failure. In practical terms, this approach allows } \\
\text { experts selecting a range of values associated with different probability of } \\
\text { occurrence instead of a single point value. }\end{array}$ \\
\hline Suitability & $\begin{array}{l}\text { Insignificant } \\
\text { limitations }\end{array}$ & NA & $\begin{array}{l}\text { This approach assumes that the probability of an event can be estimated } \\
\text { as the result of infinite similar (equal) trials in which conditions remain } \\
\text { the same, but this is hardly ever the case in real engineering systems. This } \\
\text { largely depends on the availability (data set) to determine the distribution } \\
\text { that fits the behavior of a quantity of interest. In practice, especially in } \\
\text { complex systems, this information is seldom available and if so, it might } \\
\text { need periodical updating. } \\
\text { When this approach is used with subjective expert criteria, engineers } \\
\text { might introduce uncertainty in the estimations by pre selecting a 'shape' } \\
\text { of the probability distribution based on their judgment instead of using } \\
\text { the best data available; this can also happen when no data is available } \\
\text { and the experts choose a distribution in a subjective manner. }\end{array}$ \\
\hline
\end{tabular}

Annex II -Detailed evaluation of each alternative

\section{Probabilistic approach}

Table 11. Evaluation -Probabilistic approach 


\begin{tabular}{|c|c|c|c|}
\hline \multirow[b]{2}{*}{ Effectiveness } & $\begin{array}{l}\text { Easy to } \\
\text { implement }\end{array}$ & FA & $\begin{array}{l}\text { Given required inputs and a clear workflow, the approach is easy to } \\
\text { implement. However, this is dependent on having technical experts to } \\
\text { structure the probabilistic assumptions, as well as competent } \\
\text { practitioners to execute the analysis. }\end{array}$ \\
\hline & $\begin{array}{l}\text { Easy to } \\
\text { communicate }\end{array}$ & PA & $\begin{array}{l}\text { Outputs of numerical nature can be easily informed to stakeholders as in } \\
\text { the case of individual risk indices, e.g. } 1 \times 10^{-6} \text { fatalities/year; however } \\
\text { such indices might not convey all the information associated to the } \\
\text { source of probability distribution functions or to the assumptions behind } \\
\text { their selection. Given that this alternative has been in practice for } \\
\text { decades, this criterion is judged as partially achieved as it is not ensured } \\
\text { that the uncertainty involved is explicitly accounted for and } \\
\text { communicated. }\end{array}$ \\
\hline $\begin{array}{l}\text { Software } \\
\text { available }\end{array}$ & \multicolumn{3}{|c|}{$\begin{array}{l}\text { - MATLAB (https://www.mathworks.com/products/matlab.html) } \\
\text { - R (https://www.r-project.org/) } \\
\text { - Pelican (https://www.vosesoftware.com/products/pelican/) } \\
\text { - CristalBall (https://www.oracle.com/au/middleware/technologies/crystalball.html) } \\
\text { - SIPmath (https://www.probabilitymanagement.org/sipmath) }\end{array}$} \\
\hline
\end{tabular}

\section{P-boxes}

Table 12. Evaluation -P-box

\begin{tabular}{|c|c|c|c|}
\hline Dimension & Criterion & Evaluation & Supporting comments \\
\hline \multirow[t]{2}{*}{ Suitability } & $\begin{array}{l}\text { Significant } \\
\text { advantages }\end{array}$ & FA & $\begin{array}{l}\text { Require fewer assumptions from the possible probability distribution } \\
\text { functions that fit elicited data from experts, ranging from non- } \\
\text { parametric, parametric to bounded parametric p-boxes. The less } \\
\text { assumptions, the wider the bounds for the resulting p-box. This } \\
\text { flexibility provides an alternative to Monte Carlo sampling methods, } \\
\text { which require independency assumptions and therefore additional } \\
\text { assumptions, which for complex systems might not hold. }\end{array}$ \\
\hline & $\begin{array}{l}\text { Insignificant } \\
\text { limitations }\end{array}$ & NA & $\begin{array}{l}\text { A p-box analysis requires information on the quartiles or key parameters } \\
\text { of the distribution of the variables of interest and it does not solve the } \\
\text { expert elicitation issues. Furthermore, explaining the difference between } \\
\text { a parametric or non-parametric } p \text {-box and the technical details that } \\
\text { define it might be a challenge when communicating it to decision- } \\
\text { makers. }\end{array}$ \\
\hline \multirow[b]{2}{*}{ Effectiveness } & $\begin{array}{l}\text { Easy to } \\
\text { implement }\end{array}$ & PA & $\begin{array}{l}\text { Given required inputs and a clear workflow, the approach is easy to } \\
\text { implement. However, this is dependent on having technical experts to } \\
\text { structure the probabilistic assumptions, as well as competent } \\
\text { practitioners to execute the analysis. }\end{array}$ \\
\hline & $\begin{array}{l}\text { Easy to } \\
\text { communicate }\end{array}$ & PA & $\begin{array}{l}\text { The result of P-boxes -typically a range, as in the example of the } \\
\text { compartment fire- can contribute significantly to the communication of } \\
\text { the knowledge limitations of the key inputs of the analysis, and } \\
\text { therefore of the uncertainty involved. The margin between the P-box } \\
\text { boundaries and the uncertainty it represents can be challenging to } \\
\text { communicate to the stakeholders, as well as the implications of the } \\
\text { upper bound on decision-making. }\end{array}$ \\
\hline $\begin{array}{l}\text { Software } \\
\text { available }\end{array}$ & \multicolumn{3}{|c|}{$\begin{array}{l}\text { RAMAS Risk Calc } 4.0 \text { (http://www.ramas.com/riskcalc), MATLAB, SIPmath } \\
\text { (https://www.probabilitymanagement.org/sipmath) }\end{array}$} \\
\hline
\end{tabular}

\section{Evidence theory}

Table 13. Evaluation-Evidence theory

\begin{tabular}{|c|l|c|l|}
\hline Dimension & \multicolumn{1}{|c|}{ Criterion } & Evaluation & \multicolumn{1}{c|}{ Supporting comments } \\
\hline Suitability & $\begin{array}{l}\text { Significant } \\
\text { advantages }\end{array}$ & PA & $\begin{array}{l}\text { Evidence theory does not try to describe uncertainty using a } \\
\text { measurement, but it does provide a measure of the existing evidence } \\
\text { that supports a particular subset of possibilities. A key advantage is } \\
\text { allowing for non-mutually exclusive (e.g. overlapping subsets of a }\end{array}$ \\
\hline
\end{tabular}




\begin{tabular}{|c|c|c|c|}
\hline & & & $\begin{array}{l}\text { larger fundamental set) to be computed, which is not allowed by } \\
\text { classical probability theory. Finally, the quantifiable gap between } \\
\text { Belief and Plausibility is a measure of the uncertainty, which } \\
\text { constitutes a valuable tool to evaluate different input sets for fire } \\
\text { safety engineering such as the multiple -complex and unknown- design } \\
\text { fire characteristics. }\end{array}$ \\
\hline & $\begin{array}{l}\text { Insignificant } \\
\text { limitations }\end{array}$ & NA & $\begin{array}{l}\text { This theory becomes less useful in cases where evidence is limited and } \\
\text { where the assignment of basic probability assignments transform into } \\
\text { a subjective exercise. As Denœux [134] explains, "the complexity of } \\
\text { aggregating pieces of evidence increases exponentially with the } \\
\text { number of sources", which leads to restrictions on the size of the } \\
\text { problem to be handled. }\end{array}$ \\
\hline \multirow[t]{2}{*}{ Effectiveness } & $\begin{array}{l}\text { Easy to } \\
\text { implement }\end{array}$ & PA & $\begin{array}{l}\text { There are important challenges to implement evidence theory, } \\
\text { beginning with the -often-subjective- definition of the ranges and basic } \\
\text { probability assignments used for the quantities of interest. The } \\
\text { combination of multiple inputs and then the processing can be } \\
\text { challenging if the quantities are considered dependent. This } \\
\text { implementation requires a subject expert guiding the process and } \\
\text { ensuring the desired outcome is obtained, although the availability of } \\
\text { tools such as IP Toolbox increases the ease of use. }\end{array}$ \\
\hline & $\begin{array}{l}\text { Easy to } \\
\text { communicate }\end{array}$ & PA & $\begin{array}{l}\text { As an uncertainty function that maps into the }[0,1] \text { range, the output } \\
\text { is easy to communicate. However it presents similar challenges to the } \\
\text { P-box's outputs, as it is not a point-value but bounded distributions. } \\
\text { Furthermore, the use of the evidence measurements (Belief and } \\
\text { Plausibility) increases the complexity of the information to be } \\
\text { communicated. }\end{array}$ \\
\hline $\begin{array}{l}\text { Software } \\
\text { available }\end{array}$ & \multicolumn{3}{|c|}{$\begin{array}{l}\text { - MATLAB module DSI Toolbox (Auer, A Verified MATLAB Toolbox for the } \\
\text { - Dempster-Shafer Theory) } \\
\text { - IP Toolbox for MATLAB (Philipp Limbourg - } \\
\text { https://www.mathworks.com/matlabcentral/fileexchange/9379-imprecise-probability-propagation- } \\
\text { toolbox, https://www.uni-due.de/informationslogistik/ipptoolbox.php) } \\
\text { - R package 'EvCombR' (Alexander Karlsson, 2014) } \\
\text { - R packace 'evclust' or Evidential Clustering (Thierry Denoeux, https://cran.r- } \\
\text { project.org/web/packages/evclust/index.html) } \\
\text { - IDRISI GIS Analysis in TerrSet (Clark University) } \\
\text { - Orfeo Toolbox, Fusion of Classifications application (https://www.orfeo- } \\
\text { toolbox.org/CookBook/Applications/app_FusionOfClassifications.html) } \\
\text { - GRASS GIS program 'r.dst.combine' using Dempster's Rule of Combination (Benjamin Ducke, Gavin } \\
\text { Powell, http://svn.osgeo.org/grass/grass-addons/grass6/dst/raster/r.dst.combine/description.html) }\end{array}$} \\
\hline
\end{tabular}

\section{Possibility theory}

Table 14. Evaluation -Possibility theory

\begin{tabular}{|c|l|c|l|}
\hline Dimension & \multicolumn{1}{|c|}{ Criterion } & Evaluation & \multicolumn{1}{c|}{ Supporting comments } \\
\hline Suitability & $\begin{array}{l}\text { Significant } \\
\text { advantages }\end{array}$ & PA & $\begin{array}{l}\text { Its output is a range of possible values for a variable of interest, } \\
\text { regardless of their probability. This adds a layer of information to the risk } \\
\text { picture [135]. }\end{array}$ \\
\cline { 2 - 5 } & $\begin{array}{l}\text { Insignificant } \\
\text { limitations }\end{array}$ & NA & $\begin{array}{l}\text { There is the potential of obtaining over conservative solutions, as unlikely } \\
\text { values can be found within the output. Furthermore, the subsets } \\
\text { representing the values of the variable of interest should be nested; if } \\
\text { this is not the case or cannot be ensured, evidence theory should be } \\
\text { considered instead. }\end{array}$ \\
\hline Effectiveness & $\begin{array}{l}\text { Easy to } \\
\text { implement }\end{array}$ & $\begin{array}{l}\text { There are important challenges to implement possibility theory, } \\
\text { beginning with the -often-subjective- definition of the fuzzy sets used for } \\
\text { the quantities of interest. The combination of multiple inputs and then } \\
\text { the processing can be challenging depending on the sampling of the fuzzy } \\
\text { inputs and also the defuzziphication technique selected. This }\end{array}$ \\
\hline
\end{tabular}




\begin{tabular}{|l|l|c|l|}
\hline & & $\begin{array}{l}\text { implementation requires a subject expert guiding the process and } \\
\text { ensuring the desired outcome is obtained. }\end{array}$ \\
\cline { 2 - 3 } & $\begin{array}{l}\text { Easy to } \\
\text { communicate }\end{array}$ & PA & $\begin{array}{l}\text { As in evidence theory, the outputs of possibility theory might be } \\
\text { unfamiliar to the stakeholders, specially the possibility and necessity } \\
\text { measures. }\end{array}$ \\
\hline $\begin{array}{l}\text { Software } \\
\text { available }\end{array}$ & \multicolumn{2}{|l|}{ PossibleRisk, LEDTools, IP Toolbox for MATLAB } \\
\hline
\end{tabular}

Info-gap

Table 15. Evaluation -Info-gap

\begin{tabular}{|c|c|c|c|}
\hline Dimension & Criterion & Evaluation & Supporting comments \\
\hline \multirow[t]{2}{*}{ Suitability } & $\begin{array}{l}\text { Significant } \\
\text { advantages }\end{array}$ & FA & $\begin{array}{l}\text { The outcomes of an info-gap analysis provides a quantification of } \\
\text { uncertainties that cannot be assessed form a probabilistic approach and that } \\
\text { are necessary to understand to support decision-making. In the presence of } \\
\text { unstructured uncertainties such as in the case of fire safety concerns with } \\
\text { new materials or assemblies, info-gap theory provides a functional } \\
\text { alternative to support adequate decision-making. }\end{array}$ \\
\hline & $\begin{array}{l}\text { Insignificant } \\
\text { limitations }\end{array}$ & PA & $\begin{array}{l}\text { Most engineering analysis including those of fire safety engineering employ } \\
\text { a large amount of models with irreducible -and unstructured- uncertainties, } \\
\text { both key elements to apply the info-gap approach. Given the flexibility of } \\
\text { this alternative, no significant limitations are identified except those related } \\
\text { to its implementation. }\end{array}$ \\
\hline \multirow[t]{2}{*}{ Effectiveness } & $\begin{array}{l}\text { Easy to } \\
\text { implement }\end{array}$ & NA & $\begin{array}{l}\text { An info-gap analysis requires a detailed understanding of the system, the } \\
\text { models involved and the inputs required, as well as an understanding of the } \\
\text { uncertainty sources. Although these sources can be unstructured and } \\
\text { unbounded, the info-gap is constructed based on those identified and an } \\
\text { optimization scheme is used to estimate the robustness solution. This } \\
\text { process can be mathematically demanding, requiring technical expertise for } \\
\text { its implementation. }\end{array}$ \\
\hline & $\begin{array}{l}\text { Easy to } \\
\text { communicate }\end{array}$ & PA & $\begin{array}{l}\text { Despite it does not use probabilities, the results of the robustness functions } \\
\text { should be fairly easy to communicate to stakeholder, in particular when two } \\
\text { or more competing alternatives are compared. The significance of the } \\
\text { robustness value can present significant challenges when taken out of a } \\
\text { comparative analysis. }\end{array}$ \\
\hline
\end{tabular}

\section{Strength of knowledge}

Table 16. Evaluation -Strength of Knowledge

\begin{tabular}{|l|l|c|l|}
\hline Dimension & \multicolumn{1}{|c|}{ Criterion } & Evaluation & \multicolumn{1}{c|}{ Supporting comments } \\
\hline Suitability & $\begin{array}{l}\text { Significant } \\
\text { advantages }\end{array}$ & FA & $\begin{array}{l}\text { Adding the additional layer of strength of knowledge into the risk } \\
\text { assessment, two same subjective probabilities can be judged in a very } \\
\text { different way and therefore lead to different decision making. This allows } \\
\text { explicitly stating the uncertainty behind the assumptions and the expected } \\
\text { outcomes in the assessment. A significant advantage of this approach is that } \\
\text { it can be used at all levels of risk assessment (e.g. ongoing operations, design } \\
\text { considerations) and compatible with tools such as QRA or Risk Matrices. }\end{array}$ \\
\cline { 2 - 5 } & $\begin{array}{l}\text { Insignificant } \\
\text { limitations }\end{array}$ & PA & $\begin{array}{l}\text { Agreement is required to define the criteria for the strength of knowledge } \\
\text { ordinal levels, which can be a complicated task when the assessment } \\
\text { involves personnel with very different point of views or expertise. This } \\
\text { constitutes the biggest challenge of the alternative, as the criteria can be } \\
\text { largely subjective and can diverge in the presence of stakeholders with } \\
\text { extremely different points of view. }\end{array}$ \\
\hline Effectiveness & $\begin{array}{l}\text { Easy to } \\
\text { implement }\end{array}$ & PA & $\begin{array}{l}\text { Initially, SoK approach could be considered the easiest approach to account } \\
\text { for uncertainty as it relies on a flexible scheme of qualitative levels that } \\
\text { measure the supporting evidence and knowledge of the engineers. } \\
\text { However, its actual implementation -as in the adequate use of risk analysis }\end{array}$ \\
\hline
\end{tabular}




\begin{tabular}{|l|l|l|l|}
\hline & & $\begin{array}{l}\text { matrices- must be tailored to each system and to the objectives of the } \\
\text { analysis. This increases the potential for misusing the alternative or requiring } \\
\text { considerable additional resources for properly applying it. }\end{array}$ \\
\cline { 2 - 4 } & $\begin{array}{l}\text { Easy to } \\
\text { communicate }\end{array}$ & $\begin{array}{l}\text { SoK yields a list of assumptions and limitations and the associated } \\
\text { knowledge that supports them or questions them. This not only allows for } \\
\text { ease of communication, but also constitutes an additional information layer } \\
\text { which can help formulate risk management actions. }\end{array}$ \\
\hline
\end{tabular}

\section{Exploratory Model Analysis}

Table 17. Evaluation -Exploratory Model Analysis

\begin{tabular}{|c|c|c|c|}
\hline Dimension & Criterion & Evaluation & $\begin{array}{l}\text { Supporting comments } \\
\end{array}$ \\
\hline \multirow[b]{2}{*}{ Suitability } & $\begin{array}{l}\text { Significant } \\
\text { advantages }\end{array}$ & FA & $\begin{array}{l}\text { EMA is able to explore a vast set of possible scenarios including a large } \\
\text { range of variables and variability in conditions. A statistical treatment of } \\
\text { the resulting scenarios allow identifying key conditions that would make } \\
\text { the decision alternatives inviable, hence finding robust strategies. } \\
\text { Additionally, this methodology intakes new information, leading to } \\
\text { adaptive strategies. }\end{array}$ \\
\hline & $\begin{array}{l}\text { Insignificant } \\
\text { limitations }\end{array}$ & PA & $\begin{array}{l}\text { Detailed knowledge of the system and the internal and external variables } \\
\text { that might influence its performance is needed. Furthermore, advanced } \\
\text { modelling tools and data base management is required in order to host } \\
\text { the scenarios discovery and its statistical treatment, limiting the range of } \\
\text { users for whom this methodology is viable. Not only specific } \\
\text { competences in the field of computer experiments is required, including } \\
\text { potential knowledge and skills of machine-learning and artificial } \\
\text { intelligence, but a deep knowledge of the structure of the problem is } \\
\text { required. The latter refers to the need for competent fire engineers to } \\
\text { guide the construction process of the computational experiments. This in } \\
\text { sum shows significant limitations to the methodology. }\end{array}$ \\
\hline \multirow[t]{2}{*}{ Effectiveness } & $\begin{array}{l}\text { Easy to } \\
\text { implement }\end{array}$ & PA & $\begin{array}{l}\text { Depending on the amount of conditions that require exploring and the } \\
\text { technique chosen to generate the possible universes, the } \\
\text { implementation will require more planning and technical resources such } \\
\text { as computing power. Given the existence of a well characterized model, } \\
\text { the EMA Workbench [113] can be used to run it, given that a competent } \\
\text { user leads the implementation. The latter constitutes the challenge for } \\
\text { EMA implementation, as this technique is not typically used for fire risk } \\
\text { assessments. }\end{array}$ \\
\hline & $\begin{array}{l}\text { Easy to } \\
\text { communicate }\end{array}$ & NA & $\begin{array}{l}\text { The ease of communication directly depends on the defined outcomes, } \\
\text { as well as the complexity of the model. However, the communication is } \\
\text { based on the evaluated policies and the scenario sets that yield either } \\
\text { successful or unsuccessful results. For stakeholders used to probabilistic } \\
\text { results, receiving such results could be challenging. }\end{array}$ \\
\hline $\begin{array}{l}\text { Software } \\
\text { available }\end{array}$ & \multicolumn{3}{|c|}{ R, EMA workbench (TU Delft) } \\
\hline
\end{tabular}

